\title{
Glycosylated Sertraline-Loaded Liposomes for Brain Targeting: QbD Study of Formulation Variabilities and Brain Transport
}

\author{
Ibrahim Harbi, ${ }^{1}$ Bader Aljaeid, ${ }^{1}$ Khalid M. El-Say, ${ }^{1,2}$ and Ahmed S. Zidan ${ }^{1,3,4}$
}

\begin{abstract}
Received 3 December 2015; accepted 9 January 2016; published online 19 January 2016
Abstract. Effectiveness of CNS-acting drugs depends on the localization, targeting, and capacity to be transported through the blood-brain barrier (BBB) which can be achieved by designing brain-targeting delivery vectors. Hence, the objective of this study was to screen the formulation and process variables affecting the performance of sertraline (Ser-HCl)-loaded pegylated and glycosylated liposomes. The prepared vectors were characterized for Ser- $\mathrm{HCl}$ entrapment, size, surface charge, release behavior, and in vitro transport through the BBB. Furthermore, the compatibility among liposomal components was assessed using SEM, FTIR, and DSC analysis. Through a thorough screening study, enhancement of Ser$\mathrm{HCl}$ entrapment, nanosized liposomes with low skewness, maximized stability, and controlled drug leakage were attained. The solid-state characterization revealed remarkable interaction between Ser$\mathrm{HCl}$ and the charging agent to determine drug entrapment and leakage. Moreover, results of liposomal transport through mouse brain endothelialpolyoma cells demonstrated greater capacity of the proposed glycosylated liposomes to target the cerebellar due to its higher density of GLUT1 and higher glucose utilization. This transport capacity was confirmed by the inhibiting action of both cytochalasin B and phenobarbital. Using C6 glioma cells model, flow cytometry, time-lapse live cell imaging, and in vivo NIR fluorescence imaging demonstrated that optimized glycosylated liposomes can be transported through the BBB by classical endocytosis, as well as by specific transcytosis. In conclusion, the current study proposed a thorough screening of important formulation and process variabilities affecting brain-targeting liposomes for further scale-up processes.
\end{abstract}

KEY WORDS: glycosylated liposomes; pegylation; screening; sertraline; solid-state characterization.

\section{INTRODUCTION}

Liposomes are colloidal vesicles of nanosize range formed of phospholipids and cholesterol to entrap water and lipid-soluble molecules for the purpose of drug delivery. Liposomes are shown to have significant advantage over other nanoparticulated delivery systems to deliver medications across the blood-brain barrier (BBB). The main advantage of liposomes as delivery vectors is their abilities to mask the barrier-limiting properties of the active drug molecule and the system. Moreover, it can control the drug leakage rate in different endothelial regions of the brain, hence reducing the anticipated regional toxicity (1). Several mechanisms and strategies were proposed to mediate this targeting potential and improve drug bioavailability in the brain. Surface-

\footnotetext{
${ }^{1}$ Department of Pharmaceutics and Industrial Pharmacy, Faculty of Pharmacy, King Abdulaziz University, Jeddah, 21589P.O. Box: 80260, Kingdom of Saudi Arabia.

${ }^{2}$ Department of Pharmaceutics and Industrial Pharmacy, Faculty of Pharmacy, Al-Azhar University, Cairo, Egypt.

${ }^{3}$ Department of Pharmaceutics and Industrial Pharmacy, Faculty of Pharmacy, Zagazig University, Zagazig, Egypt.

${ }^{4}$ To whom correspondence should be addressed. (e-mail: aszidan@kau.edu.sa; azidoon@yahoo.com)
}

modified liposomes with polyethylene glycol (PEG) are widely used to thwart their recognition by the reticuendothelial system (RES), hence extends their residence time in blood $(2,3)$. The specificity of liposomes toward an endothelial target can be accomplished by modifying the vesicular surface with certain homing devices, namely receptor agonists, antagonists, or antibodies (4). The functionalization of liposomes with glycolipids might attribute their specificity toward BBB glucose transporters (GLUT) which consist of several members, GLUT1-GLUT7 (5). GLUT1 mediates most of the glucose transport activity in the brain (6) and exists as two different isoforms that differed only in their extent of glycosylation. The $55-\mathrm{kDa}$ isoform is distributed at the luminal and abluminal membrane of the endothelial cells of brain capillaries. On the other hand, the other isoform, 45-kDa GLUT1, is expressed in all other endothelial cells (7). D-Glucose moieties are the essential fuel for the brain endothelial cells. At rest, brain metabolism consumes about one fifth of whole-body glucose (8). In addition, the ability of endothelial cells to consume other energy molecules is very restricted, for example, it can metabolize ketone bodies but not lipids under fasting conditions (7). In infants and children, the glucose requirement by the brain exceeds the adult's requirement by three to four folds, equivalent to four fifth of whole-body glucose consumption (9). Consequently, due to this high capacity of glucose 
utilization and transport capacity, glucose moieties are considered good candidates for transporting medications across the $\mathrm{BBB}$ for brain delivery. Surface modification of the liposomal vesicles with glucose moieties has been investigated as an approach for this purpose $(4,10)$. Qin and coworkers have utilized $\mathrm{N}$-acetyl glucosamine (NAG) as a ligand for the GLUT1 to deliver Coumarin-6, as fluorescent probe, to brain cells (11). Moreover, Xie and coworkers demonstrated that the water solubility of NAG led to greater cellular internalization capacity of the pegylated-glycosylated liposomes (12). They have also reported that high PEG surface modification may retard the targeting capacity of the liposome to endothelial cells due to the steric hindrance, whereas low content of PEG may obstruct the exposure to GLUT receptors (12).

The structural flexibility of liposomes allows not only the entrapment of hydrophilic and hydrophobic substances but also modification of vesicular surfaces with different ligands. Compared to lipid-soluble drugs, the entrapment of watersoluble medications into liposomal vesicles presents great challenges. In addition, the intensity and distribution of surface modification with different ligands and modifiers are varied considerably according to the process and formulation variables. Therefore, an exploration of employing quality by design (QbD) principles to liposomes entrapping watersoluble drug with modified surfaces will provide valuable information on the critical formulation and process variables to be controlled. In this regard, the objectives of the current case study were to understand the surface modification intensity by both PEG and NAG as well as to determine their optimal loading levels. The physicochemical description of NAG-modified pegylated liposomes were evaluated in terms of number weighted vesicular size, size distribution, zeta potential, drug entrapment efficiency, and leakage rate as a function of ten formulation and process parameters. Sertraline hydrochloride (Ser- $\mathrm{HCl}$ ) was used as model CNSacting medication for brain targeting. Sertraline has been reported to alleviate depression symptoms such as feelings of intense sadness, helplessness, worthlessness, and impaired functioning (13). Ser- $\mathrm{HCl}$ is a water-soluble drug, slowly absorbed following oral administration and undergoes extensive first-pass metabolism to N-desmethylsertraline (14). Although Ser-HCl biodistribution has been investigated (15), its transport from the systemic circulation to the brain is severely limited by the BBB (16). Hence, this study aimed to statistically screen the critical formulation and process variabilities associated with the entrapment of $\mathrm{Ser}-\mathrm{HCl}$ in glycosylated-pegylated liposomes for brain delivery. Moreover, mouse brain endothelialpolyoma middle $\mathrm{T}$ antigen transformed cell line was employed for an in vitro BBB transport model to evaluate the transendothelial capacity of glycosylated liposomes.

\section{MATERIALS AND METHODS}

Hydrogenated phosphatidylcholine (95\% hydrogenated phosphatidylcholine, $0.5 \%$ hydrogenated lysophophatidylcholine) was gifted from American Lecithin company (Oxford, CT, USA). Sertraline hydrochloride was kindly donated by Riyadh Pharma (Riyadh, KSA). Highly purified polyethylene glycol 4000 was purchased from Croda Inc. (Columbus circle edition, NJ, USA). Rhodamine (Rho) and NIR dye, 1,1 - dioctadecyl-3,3,3,3tetramethylindotricarbocyanine iodide (DiR), was purchased from Invitrogen (Carlsbad, CA, USA). BisBenzimide H 33258 and DiO, 3,3'-Dioctadecyloxacarbocyanine Perchlorate, were obtained from Beijing Fanbo Science \& Technology, Co., Ltd. (Beijing, China). Chloroform was purchased from PCCA INC. (Houston, Texas, USA). HPLC grade phosphoric acids were purchased from VWR Scientific (Bridgeport, NJ, USA). Dicetyl phosphate, N-acetyl glucosamine, cholesterol, monobasic and dibasic potassium phosphate, HPLC grade acetonitrile, and methanol were purchased from Fisher Scientific (Pittsburgh, PA, USA).

\section{Plackett-Burman Screening Design}

Plackett-Burman design of experiments was used as a QbD tool to thoroughly screen ten formulation and process variables (Table I). The formulation factors included phospholipid (X1), cholesterol (X2), dicetyl phosphate (X3), NAG (X4), PEG 4000 (X5), and Ser-HCl (X6) loading concentrations. On the other hand, processing variables to prepare the proposed vesicles encompassed methanol percentage in chloroform to dissolve the lipid pool (X7), hydration time (X8), sonication amplitude (X9), and sonication time (X10). These factors were evaluated to be critical to liposomes' performance based on a risk analysis study (data not shown). Each variables in the screening study was evaluated at the specified lowest $(-1)$ and highest $(+1)$ levels based on the results of the preliminary investigations (Table I). To both improve the prediction performance of the design and assess the factors' collinear trends on the responses, three center point batches were included in the design (F7-F9). The investigated responses included $\mathrm{Ser}-\mathrm{HCl}$ entrapment efficiency (Y1), number weighted vesicular size (Y2), size distribution as expressed by skewness values of size distribution curves (Y3), electrical properties as expressed by zeta potential values (Y4), Ser-HCl leakage percentages as expressed by both initial release percentage after $2 \mathrm{~h}(\mathrm{Q} 2 \mathrm{~h}, \mathrm{Y} 5)$, and delayed release percentage after $24 \mathrm{~h}$ (Q24h, Y6). Multiple regression and ANOVA were performed to analyze the data. Moreover, a series of Pareto charts, contour and surface plots were developed to demonstrate the individual influence of each variable on the responses.

\section{Liposome Preparation}

Glycosylated and pegylated unilamellar liposomal vesicles were prepared using the thin-film hydration technique as described by $\mathrm{Xu}$ and coworkers with some modifications (17). Fifteen liposomal batches were prepared by dissolving the specified amounts of phosphatidylcholine, cholesterol, dicetyl phosphate, NAG, and PEG 4000 in $40 \mathrm{~mL}$ of chloroformmethanol mixtures according to the working amounts listed in Table I. Organic solvents were evaporated under vacuum using R10 Buchi Rotavapor (BÜCHI Labortechnik AG, Postfach, Flawil, Switzerland) at $60^{\circ} \mathrm{C}$ to form thin films. The films were then purged with nitrogen followed by overnight vacuum drying at $30^{\circ} \mathrm{C}$. Multilamellar liposomes were assembled by hydrating the dry lipid films at $60^{\circ} \mathrm{C}$ with the specified $20 \mathrm{~mL}$ isotonic $\mathrm{Ser}-\mathrm{HCl}$ for the respective hydration times in Table I. Borosilicate glass beads were used to disrupt the 


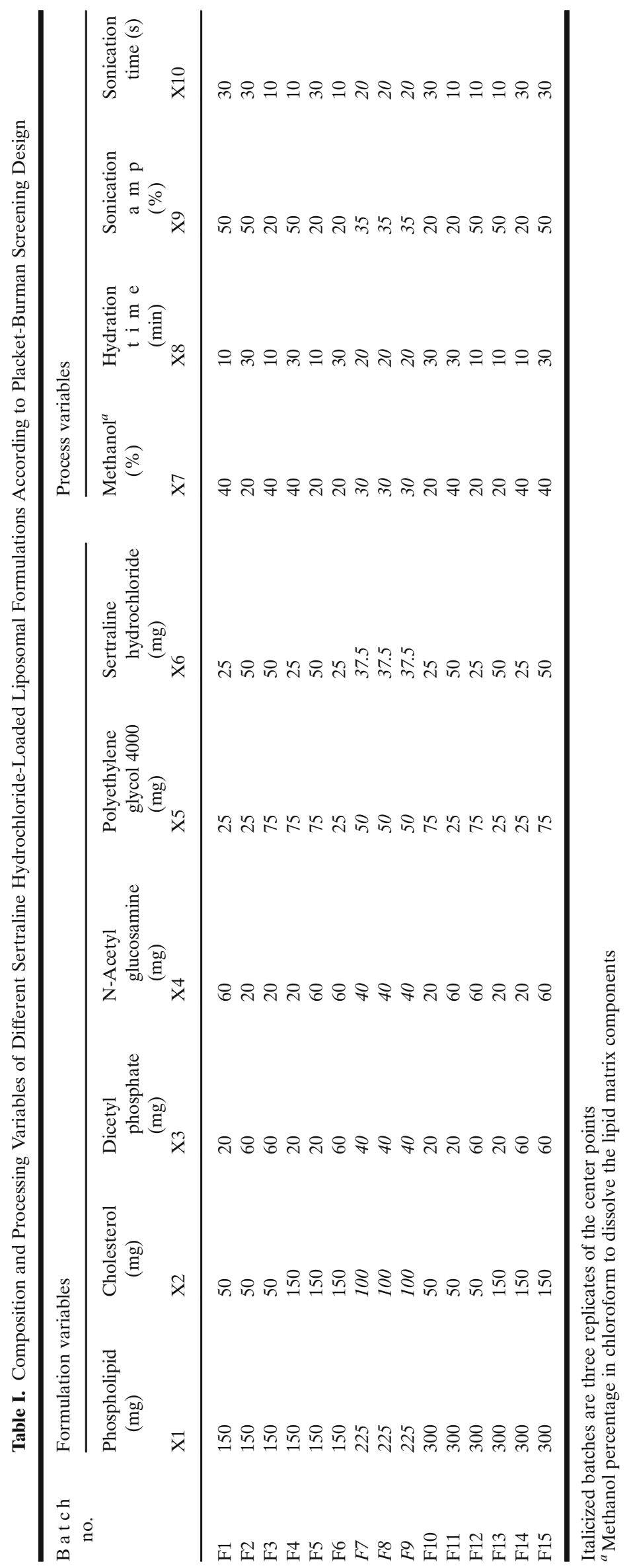


formed films during hydration. These hydration times were sufficient to completely disrupt the lipids and creamy, milky liposomal suspensions resulted in. Liposomal vesicles were then subjected to size reduction using a probe sonicator (Q125 probe sonicator, Qsonica, LLC., Newtown, CT, USA) at the respective sonication amplitudes and times (Table I). Liposomal suspensions were then subjected to 5 cycles of freeze and thawing $\left(20 \mathrm{~min}\right.$ at $-70^{\circ} \mathrm{C}$ and $5 \mathrm{~min}$ at $60^{\circ} \mathrm{C}$ with $1 \mathrm{~min}$ vortexing among cycles) to optimize Ser-HCl encapsulation (17). During these cycles, freezing was performed using ultra-low temperature freezer (MR-DF-N86 Series, Labfreez Instruments Co., Ltd., Xiangtan, Hunan, China) while the thawing was performed using a heated water bath. After two washing cycles, the unentrapped drug was removed by ultracentrifugation (Sorvall WX 100+ Ultracentrifuge, Thermo Fisher Scientific Co., Waltham, MA, USA) of 90,000 rpm for $90 \mathrm{~min}$ at $2^{\circ} \mathrm{C}$. The resultant liposomal residue was then reconstituted with $2 \mathrm{~mL}$ of $10 \mathrm{mM}$ pH 7.4 HEPES (4-(2hydroxyethyl)-1-piperazine ethanesulfonic acid) buffer and stored at $-2^{\circ} \mathrm{C}$ for further analysis. HEPES buffer has been used employed due to its compatibility with the endothelialpolyoma middle $\mathrm{T}$ antigen transformed cells.

\section{Entrapment Efficiency}

The free sertraline hydrochloride was assessed after ultracentrifugation using an in-house developed and validated chromatographic analysis. Separation was performed using HPLC Agilent 1200 LC Quaternary series pump coupled with Agilent 1200 high-performance autosampler (Agilent technologies Inc., Santa Clara, CA, USA). Phenomenex Luna C18 column $(250 \mathrm{~mm} \times 4.6 \mathrm{~mm}, 5 \mathrm{um}$, Phenomenex Co., Torrance, CA, USA) and Zorbax C18 column $(12.5 \times 4.6 \mathrm{~mm}, 5 \mathrm{um}$, Agilent technologies Inc., Santa Clara, CA, USA) guard column were used. The mobile phase consisted of $10 \mathrm{mM}$ ammonium formate buffer $(\mathrm{pH} 4.5)$ and acetonitrile at 20:80 v/v ratio and was pumped isocratically at a flow rate of $1.3 \mathrm{~mL} /$ min and column temperature of $35^{\circ} \mathrm{C}$. Detector wavelength was fixed at $220 \mathrm{~nm}$ and injection volume was $20 \mu \mathrm{L}$. The entrapment efficiency (EE) of the sertraline hydrochloride in the liposomes after sonication was calculated as percentage of the initial experimental loading as follows:

Entrapment efficiency $=\frac{\text { drug }_{\text {total }}-\text { drug }_{\text {free }}}{\text { drug }_{\text {total }}} \times 100 \%$

\section{Vesicular Size and Surface Charge}

Number weighted vesicular size and the corresponding size distribution, expressed as skewness values of size distribution curves, of the liposomal suspensions were determined by dynamic light scattering with a Nanotrac ${ }^{\circledR}$ sizing system (Microtrac Inc, Montgomeryville PA, USA) with a scattering angle of $90^{\circ}$ at $25^{\circ} \mathrm{C}$. Samples were diluted approximately 20 times using $10 \mathrm{mM} \mathrm{pH} \mathrm{7.4} \mathrm{HEPES} \mathrm{buffer} \mathrm{before}$ measurement.

Analysis of the electrical properties, expressed by the resultant zeta potential, and stability of the produced liposomal suspensions was performed by assessing their electrophoretic mobilities with the Nanotrac ${ }^{\circledR}$ system. The same samples employed for vesicular sizing were used for zeta-potential assessment. All measurements were performed at $25^{\circ} \mathrm{C}$ and in triplicate and reported as mean \pm standard deviation.

\section{In Vitro Drug Release (Leakage) Study}

Using cellulose ester membranes (MWCO of $20 \mathrm{kD}$, Spectrum Laboratories, Los Angeles, CA), the percentages of Ser-HCl diffused after 2 and $24 \mathrm{~h}$ were selected for the design input. In vitro leakage of Ser- $\mathrm{HCl}$ from the prepared vesicles was evaluated using a modified dialysis technique. In brief, the experiment setup encompassed a backing membrane reservoir of the liposomal suspension attached to the basket of USP apparatus I. Holders of perforated stainless steel discs of $2.5 \mathrm{~cm}$ inner diameter and $3 \mathrm{~mm}$ edge height were used to hold the backing membrane reservoirs. Cellulose ester membranes were then mounted at one end of the discs whereas the other end of the discs was sealed with glass cylinder of the same diameter. The reconstituted liposomal suspensions equivalent to $20 \mu \mathrm{g} / \mathrm{mL}$ Ser-HCl were added into the glass cylinders and immediately sealed to avoid drying. The backing membrane reservoir was then attached to the hollow glass cylinder, and the cell was used as the donor compartment of the USP apparatus I. Five hundred milliliters of $10 \mathrm{mM}$ phosphate buffer ( $\mathrm{pH}$ 7.4) and maintained at $37^{\circ} \mathrm{C}$ was used as the receptor medium. At a stirring rate of $100 \mathrm{rpm}, 1 \mathrm{~mL}$ aliquots were withdrawn from the receptor medium at 1, 2, 3, 4, 5, 6, 8, and $24 \mathrm{~h}$ intervals and replaced with the same volume of fresh buffer. Samples were analyzed by the developed HPLC analytical method after proper dilutions. To further deduce the mechanism of the Ser-HCl release from the prepared liposomal formulations, the release data were mathematically processed according to zero-order, first-order, diffusion, and Korsmeyer-Peppas release kinetics models.

\section{Solid-State Characterization}

The morphology of reconstituted vesicles of highest drug entrapment (Batch F3) was assessed using scanning electron microscopy (SEM) (JSM-6390 LV, JEOL, Akishima, Tokyo, Japan) at an accelerated voltage of $15 \mathrm{kV}$. Samples were gold sputter coated before SEM mounting under high vacuum of $45 \mathrm{mTorr}$ and voltage of $30 \mathrm{mV}$.

Lyophilized liposomal dispersion of the same formulation was then used for solid-state characterization by Fourier transform infrared spectroscopy (FTIR) and thermal analysis with differential scanning calorimetry (DSC). Lyophilization was performed using a benchtop freeze-drier (Labconco Corp., Kansas City, MO, USA). For this purpose, a freshly reconstituted liposomal dispersion was filled into glass vial with $10 \%(w / v)$ of sucrose as cryoprotectant. The vial was then transferred to the drying chamber then subjected to a freezing stage at $-50^{\circ} \mathrm{C}$ for $3 \mathrm{~h}$, a drying stage at $-30^{\circ} \mathrm{C}$ and 0.04 mbar pressure for $24 \mathrm{~h}$ followed by another drying stage at $25^{\circ} \mathrm{C}$ and $0.05 \mathrm{mbar}$ pressure for $24 \mathrm{~h}$. The obtained freezedried liposomal powder was kept at $-4^{\circ} \mathrm{C}$ for further analysis. FTIR spectra of liposomal powder, individual components, and the corresponding physical mixture at the same loading ratios were collected using a Nicolet ${ }^{\mathrm{TM}}$ iS $^{\mathrm{TM}} 50$ FTIR 
spectrometer (Thermo Fisher Scientific Inc., Madison, WI, USA). On the other hand, DSC analysis of the same samples was performed using DSC Q20 analyzer (TA Instruments Co., New Castle, DE, USA). For this purpose, 2-3 mg samples were packed in hermetically sealed aluminum pans followed by heating at a ramp of $10^{\circ} \mathrm{C} / \mathrm{min}$ from 25 to $300^{\circ} \mathrm{C}$ under nitrogen atmosphere.

\section{In Vitro BBB Transport Model}

Mouse brain endothelialpolyoma middle $\mathrm{T}$ antigen transformed cell line (bEnd.3, ATCC® CRL-2299' ${ }^{\mathrm{TM}}$, American Type Culture Collection, Manassas, VA, USA) of passage between 20 and 30 were employed for the BBB transport study. Endothelial cells were seeded on $2 \%$ gelatin-coated culture cell inserts at a density of $4.3 \times 10^{4}$ cells per filter and grown for 3 days. The plated cells were then incubated with DMEM supplemented with $10 \% \mathrm{FBS}, 2 \mathrm{mmol} / \mathrm{L} \mathrm{L}$-glutamine, $100 \mu \mathrm{g} / \mathrm{mL}$ endothelial cell growth factor (VEGF), $100 \mathrm{U} / \mathrm{mL}$ penicillin, and $100 \mu \mathrm{g} / \mathrm{mL}$ streptomycin. Cells were maintained at $5 \% \mathrm{CO}_{2}, 95 \%$ relative humidity, and $37^{\circ} \mathrm{C}$. The cells were allowed to adhere for $24 \mathrm{~h}$ and the culture media was replaced every other day until the cells reached approximately $80 \%$ confluency. The cells were then subcultured on 12 transwell inserts for unidirectional transport experiment of drug-loaded liposomal vesicles. To test the integrity of the monolayer, cells' tightness was assessed by measuring the transendothelial electrical resistance (TEER) with a Millicell ERS-2 Voltohmmeter (Millipore Corporation, Billerica, MA, USA). After appropriate treatment, liposomal dispersion of the optimized formulation equivalent to $20 \mu \mathrm{g} / \mathrm{mL}$ Ser- $\mathrm{HCl}$ was added onto the apical side of the BBB model. At 2, 4, 8, 12, and $16 \mathrm{~h}$ intervals, aliquots were withdrawn from the basolateral side for sertraline assay using the abovementioned chromatographic analysis method after appropriate dilution. Triplicate samples were performed and the accumulated permeated sertraline percentage was calculated by dividing the accumulated amount of the drug recovered in the basolateral side by its initial concentration in the apical side multiplied by 100 .

For transport inhibition study, either $0.07 \mathrm{M} / \mathrm{mL}$ cytochalasin B or $50 \mu \mathrm{M} / \mathrm{mL}$ phenobarbital as transport inhibitors were added to the apical chamber and incubated with the bEnd. 3 cells at $37^{\circ} \mathrm{C}$ for $30 \mathrm{~min}$. Following this preincubation with the inhibitors, the permeation study was performed the same as described before.

\section{C6 Glioma Cellular Uptake}

Fluorescent dye-labeled liposomes of the optimized formulation were prepared by dissolving the lipid film in anhydrous alcohol solution of the fluorescent dye, namely rhodamine (Rho) or 1,1 -dioctadecyl-3,3,3,3 tetramethylindotricarbocyanine iodide (DiR). This alcoholic solution was then evaporated to dryness under vacuum with a rotary evaporator to obtain a thin-labeled lipid film. Fluorescent dye-labeled liposomes were then formed by hydrating this film as described before. C6 glioma cells (ATCC® CCL$107^{\mathrm{TM}}$ ) were obtained from American Type Culture Collection, Manassas, VA, USA. The cells were maintained in Dulbecco's modified Eagle's medium (DMEM, Gibco ${ }^{\circledR}$ Life Technologies, Grand Island, NY, USA) supplemented with
$10 \%$ FBS and antibiotics $(100 \mathrm{U} / \mathrm{mL}$ penicillin and $100 \mu \mathrm{g} /$ $\mathrm{mL}$ streptomycin). The cells were seeded into six-well plates and cultured overnight at $37^{\circ} \mathrm{C}$, followed by treating with either free Rho, Rho-labeled non-glycosylated optimized liposomes, Rho-labeled glycosylated optimized liposomes or $50 \mu \mathrm{M} / \mathrm{mL}$ phenobarbital for $2 \mathrm{~h}$ followed by Rho-labeled glycosylated optimized liposomes. The DMEM culture medium was used as a blank control and the cells were further cultured for $4 \mathrm{~h}$ followed by trypsinizing and harvesting. The fluorescence intensities of liposomes in cells were assessed with a FACS scan flow cytometer (BD FACSARIA III, Mountain View, CA, USA) (18). The wavelength of the Rho emission was $560 \mathrm{~nm}$, and a FL2-H filter $(580 \pm 21 \mathrm{~nm})$ was used to detect fluorescence intensities. Ten thousand events were acquired, and the data were analyzed using FlowJo 7.6 software.

For the time-lapse live cell imaging, $\mathrm{C} 6$ glioma cells were seeded onto plates, and after appropriate treatment as described before, the cells were visualized with a microscope system. Briefly, C6 glioma cells were seeded into plates (Applied Precision, Issaquah, WA, USA) and cultured overnight at $37^{\circ} \mathrm{C}$. Cells were then stained with $10 \mu \mathrm{g} / \mathrm{mL}$ bisBenzimide H 33258 and $6 \mu \mathrm{g} / \mathrm{mL}$ DiO followed by washing with PBS. After treating with Rho-labeled non-glycosylated optimized liposomes, Rho-labeled glycosylated optimized liposomes into the wells, images were captured using a DeltaVision microscope system (Applied Precision, Issaquah, WA, USA). In the inhibition assay, cells were treated with $50 \mu \mathrm{M} / \mathrm{mL}$ phenobarbital for $2 \mathrm{~h}$ followed by Rho-labeled glycosylated optimized liposomes. Time-lapse images during $30 \mathrm{~min}$ treatment were collected and analyzed statistically using DeltaVision SoftWoRx software (Applied Precision, Issaquah, WA, USA).

\section{RESULTS AND DISCUSSION}

The efficacy of liposome-entrapped biomaterials and/or small molecules in the control of diseases is dependent upon the target selectivity of liposomes. This target selectivity can be accomplished by modifying vesicular surfaces with active moieties with affinities toward the target site. The presence and distribution of GLUT on different regions of the brain permits both sugar-specific and cell type-specific uptake of glycosylated ligands via adsorptive endocytosis (19). Therefore, this approach was implemented in the current study with an emphasis on the surface interaction of glucose moieties and/or PEG at the liposomal surfaces to alter their physicochemical properties. In addition, the influences of the formulation and processing variabilities on the resultant EE, vesicular size, size distribution, zeta potential, and release characteristics of the entrapped CNS-acting medication. A risk assessment strategy was also adopted to reduce the number of risk variables that might affect the critical liposomal properties to ten high risk variables.

\section{Sertraline Entrapment Efficiency}

Ten high-risk formulation and processing variables were evaluated for their influence on liposome capacity to entrap Ser-HCl. For the different variables' combinations, Table II demonstrated that the Ser-HCl EE ranged from 5.4\% (F10) to 98.1\% (F3). Results of the regression analysis in Table III and 
Table II. Characterization of the Prepared Sertraline Hydrochloride-Loaded Liposomal Formulations (Measurements were Performed in Triplicates with Standard Deviation Values Did Not Exceed 5\% of the Stated Responses' Values)

\begin{tabular}{|c|c|c|c|c|c|c|}
\hline \multirow[t]{3}{*}{ Batch no. } & \multirow{3}{*}{$\begin{array}{l}\text { Drug entrapment } \\
\text { efficiency }(\%) \\
\text { Y1 }\end{array}$} & \multirow{3}{*}{$\begin{array}{l}\text { Number-weighted } \\
\text { vesicular size }(\mathrm{nm}) \\
\text { Y2 }\end{array}$} & \multirow{3}{*}{$\begin{array}{l}\text { Skewness } \\
\text { Y3 }\end{array}$} & \multirow{3}{*}{$\begin{array}{l}\text { Zeta potential }(\mathrm{mV}) \\
\text { Y4 }\end{array}$} & \multicolumn{2}{|c|}{ Drug release parameters ${ }^{a}$} \\
\hline & & & & & Q2h (\%) & Q24h (\%) \\
\hline & & & & & Y5 & \\
\hline $\mathrm{F} 1$ & 63.4 & 35.1 & 0.84 & 72.5 & 10.3 & 74.2 \\
\hline $\mathrm{F} 2$ & 50.2 & 86.3 & 0.54 & 83.2 & 11.8 & 72.6 \\
\hline F3 & 98.1 & 122.4 & 0.23 & 85.0 & 7.2 & 45.3 \\
\hline $\mathrm{F} 4$ & 71.5 & 113.9 & 0.89 & 106.1 & 32.5 & 93.7 \\
\hline F5 & 22.1 & 99.4 & 0.77 & 56.6 & 11.9 & 59.5 \\
\hline F6 & 13.7 & 147.3 & 0.55 & 34.8 & 12.8 & 73.7 \\
\hline$F 7$ & 34.8 & 82.7 & 0.81 & 42.6 & 11.2 & 48.8 \\
\hline$F 8$ & 41.9 & 61.4 & 0.77 & 48.7 & 13.2 & 58.6 \\
\hline$F 9$ & 31.2 & 85.4 & 0.82 & 45.6 & 9.9 & 43.9 \\
\hline F10 & 5.4 & 54.5 & 0.96 & 22.8 & 1.5 & 13.6 \\
\hline F11 & 28.2 & 51.3 & 0.79 & 24.5 & 2.3 & 20.4 \\
\hline F12 & 21.7 & 54.2 & 0.59 & 14.9 & 0.8 & 12.5 \\
\hline F13 & 15.9 & 82.2 & 0.75 & 26.4 & 20.9 & 63.1 \\
\hline F14 & 14.2 & 101.7 & 0.77 & 23.3 & 10.7 & 35.4 \\
\hline F15 & 30.9 & 81.3 & 0.64 & 7.3 & 4.3 & 21.9 \\
\hline
\end{tabular}

Italicized batches are three replicates of the center points

${ }^{a}$ Q2h and Q24h are percentage of sertraline hydrochloride released after 2 and $24 \mathrm{~h}$, respectively

Pareto charts of Fig. 1 revealed that the most significant variable to affect EE was phospholipid loading followed by methanol percentage in the organic solvent then cholesterol, NAG loadings, and sonication amplitude $(p<0.05)$. One of the advantages of multiple regression analysis is its capability to predict the investigated response based on a prediction equation that explains response-variables relationships with an acceptable accuracy. The confidence level of the proposed prediction equation of Ser- $\mathrm{HCl}$ was $91.7 \%$. Linear correlation was obtained by plotting the observed against the predicted EE values with $R^{2}$ value of 0.9764 and root mean square error of $7.3 \%$ (Fig. 2). Moreover, the distribution of the EE residual values for all formulations approximately followed the fitted normal distribution pattern with a random scattering around zero to indicate normality (Fig. 2). Half-normal plot showed that $t$ ratio values lie approximately along a straight line to

Table III. Results of Multiple Regression Analysis for Prediction of the Investigated Responses

\begin{tabular}{|c|c|c|c|c|c|c|c|}
\hline Factors & & $\begin{array}{l}\text { Drug entrapment } \\
\text { efficiency (\%) }\end{array}$ & $\begin{array}{l}\text { Number-weighted } \\
\text { vesicular size }(\mathrm{nm})\end{array}$ & Skewness & $\begin{array}{l}\text { Zeta potential } \\
\qquad(\mathrm{mV})\end{array}$ & $\begin{array}{l}\text { Q2h } \\
\quad(\%) *\end{array}$ & $\begin{array}{l}\text { Q24h } \\
\quad(\%)^{a}\end{array}$ \\
\hline \multirow[t]{2}{*}{ Intercept } & Estimate & 35.54 & 83.92 & 0.75 & 46.32 & 11.09 & 49.17 \\
\hline & $p$ value & $<0.0001$ & $<0.0001$ & $<0.0001$ & $<0.0001$ & 0.0002 & $<0.0001$ \\
\hline \multirow[t]{2}{*}{ Phospholipid (mg) (X1) } & Estimate & 16.90 & 14.96 & 0.01 & -26.59 & -4.44 & -21.04 \\
\hline & $p$ value & 0.0013 & 0.0124 & 0.4724 & 0.0005 & 0.0081 & 0.0002 \\
\hline \multirow[t]{2}{*}{ Cholesterol (mg) (X2) } & Estimate & 8.25 & 18.53 & -0.01 & -4.04 & -5.33 & -9.02 \\
\hline & $p$ value & 0.0174 & 0.0059 & 0.527 & 0.1911 & 0.0042 & 0.0045 \\
\hline \multirow[t]{2}{*}{ Dicetyl phosphate (mg) (X3) } & Estimate & 1.83 & -13.09 & -0.09 & 5.02 & -3.11 & -5.29 \\
\hline & $p$ value & 0.4343 & 0.0194 & 0.0025 & 0.0224 & 0.0266 & 0.028 \\
\hline \multirow{2}{*}{$\begin{array}{l}\text { N-acetyl glucosamine } \\
(\mathrm{mg})(\mathrm{X} 4)\end{array}$} & Estimate & -6.26 & -7.73 & 0.05 & 11.34 & -3.98 & -5.10 \\
\hline & $p$ value & 0.0412 & 0.0893 & 0.0241 & 0.0116 & 0.0118 & 0.0313 \\
\hline \multirow{2}{*}{$\begin{array}{l}\text { Polyethylene glycol } 4000 \\
\text { (mg) (X5) }\end{array}$} & Estimate & 5.36 & 1.84 & 0.04 & 2.32 & -0.33 & -7.72 \\
\hline & $p$ value & 0.0638 & 0.6226 & 0.0479 & 0.417 & 0.7321 & 0.0679 \\
\hline \multirow{2}{*}{$\begin{array}{l}\text { Sertraline hydrochloride } \\
\quad(\mathrm{mg})(\mathrm{X} 6)\end{array}$} & Estimate & 4.64 & -1.33 & -0.02 & 0.72 & 1.45 & 1.67 \\
\hline & $p$ value & 0.0928 & 0.7212 & 0.1646 & 0.794 & 0.1863 & 0.3467 \\
\hline \multirow[t]{2}{*}{ Methanol (\%) (X7) } & Estimate & 14.75 & -1.54 & 0.04 & 6.67 & 1.18 & -0.38 \\
\hline & $p$ value & 0.0022 & 0.6789 & 0.0297 & 0.5604 & 0.2624 & 0.82 \\
\hline \multirow[t]{2}{*}{ Hydration time (min) (X8) } & Estimate & -2.93 & 3.28 & -0.01 & 0.01 & 0.83 & 0.53 \\
\hline & $p$ value & 0.237 & 0.3973 & 0.5199 & 0.9993 & 0.4132 & 0.752 \\
\hline \multirow[t]{2}{*}{ Sonication amp (\%) (X9) } & Estimate & -6.00 & -10.28 & -0.03 & 5.28 & 3.26 & 7.54 \\
\hline & $p$ value & 0.0467 & 0.0411 & 0.0598 & 0.109 & 0.0229 & 0.0086 \\
\hline \multirow{2}{*}{ Sonication time (s) (X10) } & Estimate & -5.25 & -9.39 & 0.01 & -2.17 & 2.62 & 2.67 \\
\hline & $p$ value & 0.0674 & 0.0532 & 0.4991 & 0.4459 & 0.0446 & 0.1635 \\
\hline
\end{tabular}

Italicized batches are three replicates of the center points

${ }^{a} \mathrm{Q} 2 \mathrm{~h}$ and Q24h are percentage of sertraline hydrochloride released after 2 and $24 \mathrm{~h}$, respectively 

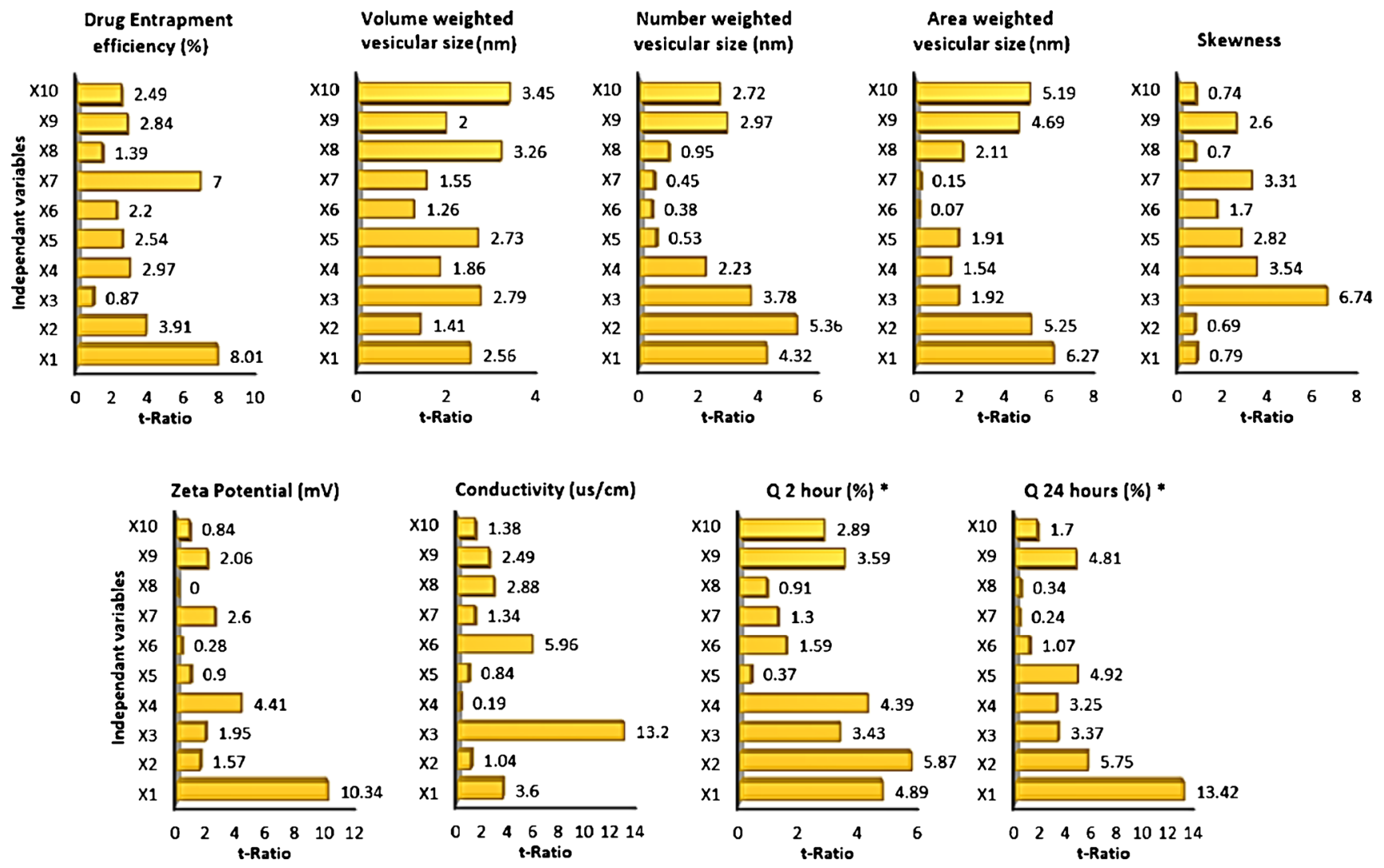

Fig. 1. Pareto charts showing the standardized effect of the investigated variables on the studied responses. $Q 2 h$ and $Q 24 h$ are percentage of sertraline hydrochloride released after 2 and $24 \mathrm{~h}$, respectively. X1-10 are phospholipid, cholesterol, dicetyl phosphate, N-acetyl glucosamine, polyethylene glycol 4000 and sertraline hydrochloride weight loadings, methanol volume, hydration time, sonication amplitude, and sonication time, respectively

exclude any severe non-normality in data. Therefore, the EE prediction model was sufficient to interpret the factors' relationships and Ser-HCl EE percentage can then be calculated within the proposed experimental design space from the following reduced linear model equation.

$$
\begin{aligned}
\text { Ser-HCIEE } \%=35.3 & +16.8 *\left[\frac{[\mathrm{X} 1-225]}{75}\right] \\
& +8.2 *\left[\frac{\mathrm{X} 2-100}{50}\right]-6.2 *\left[\frac{\mathrm{X} 4-40]}{20}\right]-5.9 *\left[\frac{\mathrm{X} 9-35}{15}\right]
\end{aligned}
$$

The "estimate" values in Table III shows the corresponding strength of each variable to affect the response relative to the other variables. The greater the absolute value of the estimate the more the influence of that factor on the investigated response. The mathematical sign of the estimate indicates the trend's direction. A positive mathematical sign of an estimate elucidates a direct correlation of a factor with the investigated response; however, a negative mathematical sign exemplifies an inverse correlation. Studying the significant formulation factors, the obtained results in Table III demonstrated that phospholipid and cholesterol loadings exhibited direct correlations with Ser-HCl EE (Fig. 3). However, decreasing NAG loading and sonication amplitude contributed to higher drug EE (Table III). The positive influence of phospholipid loading can be attributed to the increase in number of formed liposomal vesicles rather than increasing vesicular size. Accordingly, larger cumulative internal aqueous phase within the unilamellar vesicles was available for the entrapment process (20). The effect of cholesterol to augment Ser$\mathrm{HCl} \mathrm{EE}$ could be explained by its influence to increase the lamellar rigidity, hence greater bilayers' stability with reduced leakage to enhance the entrapment capacity would resulted in (21). Despite being nonsignificant to drug EE, dicetyl phosphate exhibited a positive effect due to its charge-charge interaction with the ionized form sertraline base (22). This dicetyl phosphate effect would mediate the observed NAG effect to reduce Ser-HCl EE. The positively charged ammonium moieties of NAG would compete with positive sertraline ions at vesicular surface and aqueous phase to interact with the negatively charged dicetyl phosphate sites (10). Hence, at low Ser-HCl entrapment, the intensity of surface bound drug decreased by increasing NAG loading within liposomal matrix when the lipid pool volume remained the same.

Regarding the process factors, a significant positive influence was observed for methanol percentage on Ser-HCl EE. On the other hand, negative effects were observed for the hydration time, sonication amplitude, and sonication time on the resultants EEs with only significant effect by sonication amplitude $(p<0.05)$ (Table III and Fig. 1). Increasing the films' hydration time resulted in a substantial leakage of Ser$\mathrm{HCl}$ out of vesicular aqueous phase to the dispersion aqueous medium. This action was facilitated by the temperature of hydration $\left(60^{\circ} \mathrm{C}\right)$ that was more than the phospholipid 

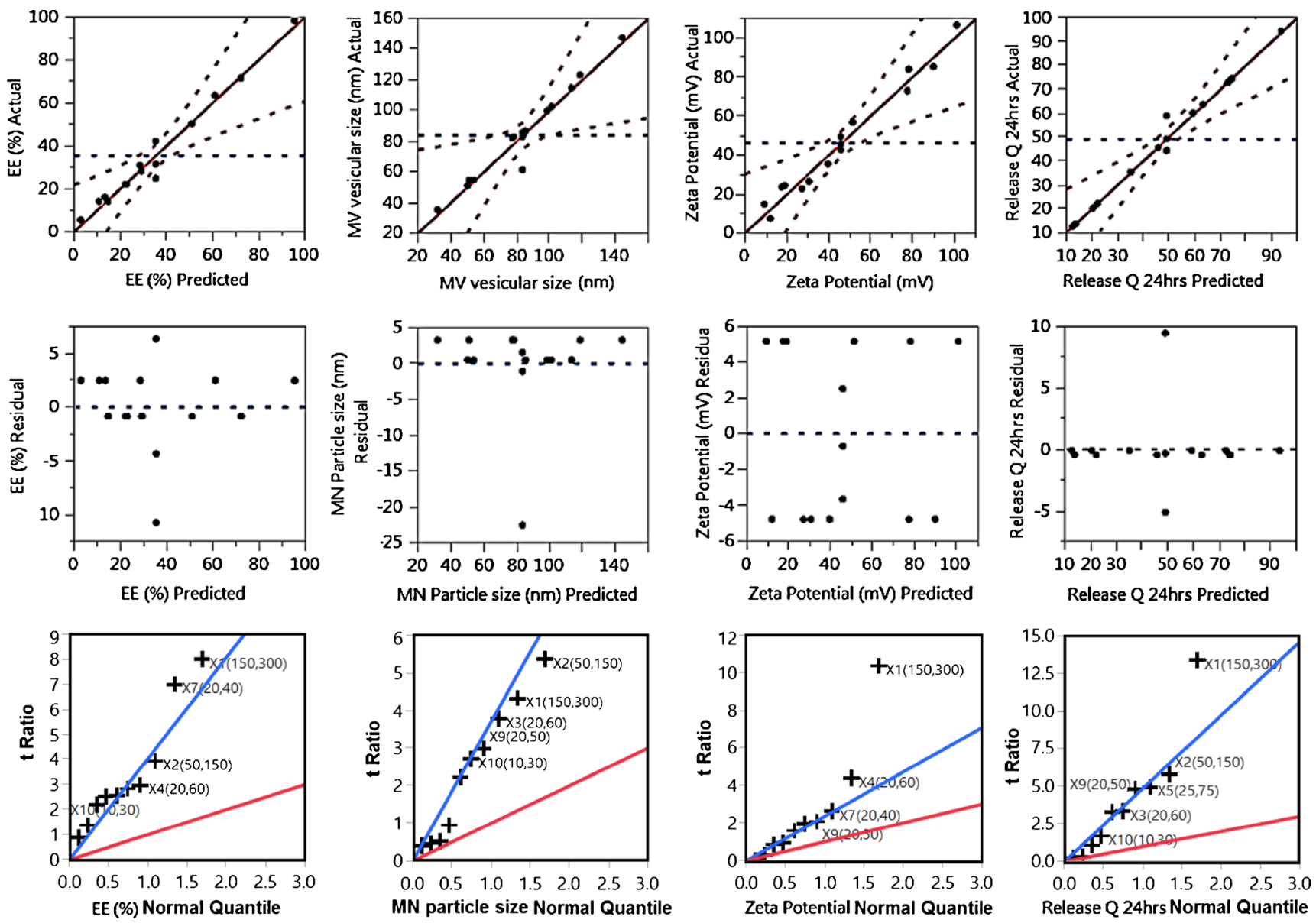

Fig. 2. Quantile-quantile, predicted versus the residuals and half-normal plots for predicting the investigated responses. ( $E E$ is drug entrapment efficiency, $M N$ vesicular size is the number-weighted vesicular size; $Q 24 \mathrm{~h}$ is percentage of sertraline hydrochloride released after $24 \mathrm{~h}$ )

transition temperature $\left(53^{\circ} \mathrm{C}\right)$; hence, enhanced mobility of lipid side chain for drug partitioning and rapid diffusion existed (23). The influence of the sonication parameters to decrease Ser-HCl EE could be explained by the reassembly of the lipid molecules to form smaller vesicles with a reduced internal aqueous compartment, hence facilitated drug leakage (24). The resultant liposomal sizes and size distributions could augment this assumption. As shown in Tables II and III, significant effect of the sonication amplitude was observed on the number weighted liposomal size, whereas it was nonsignificant on size distribution.

\section{Vesicular Size and Size Distribution}

To explore the influence of the formulation and process variables on both vesicular size and extent of size distribution expressed by the resultant skewness value of size distribution curves, the vesicular size was evaluated in a number weighing. For large polydisperse distributions, the number-weighted radius distribution would overcome the radius dependence on different length scales, particle density, and scattering angle (25). Therefore, it was preferred over both intensity and volume weighted size distributions to determine the investigated vesicular radius. The obtained results demonstrated a significant size reduction of the prepared vesicles after sonication. Increasing the applied number of freeze-thaw cycles from 5 to 9 cycles did not significantly increase the vesicular sizes.
Moreover, the vesicular size distribution became more homogeneous after 5 cycles. Hence, this factor was kept constant at 5 cycles for all formulations.

Table II demonstrates that the number-weighted sizes of the prepared liposomes varied from $35.1 \mathrm{~nm}$ with a skewness value of 0.84 to $147.3 \mathrm{~nm}$ with a skewness value of 0.55 for formulations F1 and F6, respectively. Highest and lowest skewness values of 0.96 and 0.23 were recorded for formulations F10 and F3, respectively. Table III and Fig. 1 showed that the most significant $(p<0.05)$ factors affecting the resultant vesicular sizes were cholesterol loading followed by phospholipid then dicetyl phosphate loadings and sonication amplitude. The obtained results showed that increasing both cholesterol and phospholipid experimental loadings resulted in larger vesicles formation (Table III). On the other hand, increasing dicetyl phosphate loading and sonication amplitude were associated with significant decrease in vesicular size (Table III and Fig. 3). Regarding the size distribution, skewness values decreased significantly by increasing dicetyl phosphate and NAG loadings with more pronounced effect for dicetyl phosphate (Table III).

It is worth noting that the applied ultrasound energy reduced both resultant vesicular sizes to unilamellar vesicles and the corresponding skewness values to indicate homogenous size distributions. For example, most formulations showed vesicular sizes more than $2500 \mathrm{~nm}$ with skewness values more than 0.8 before sonication, whereas after 

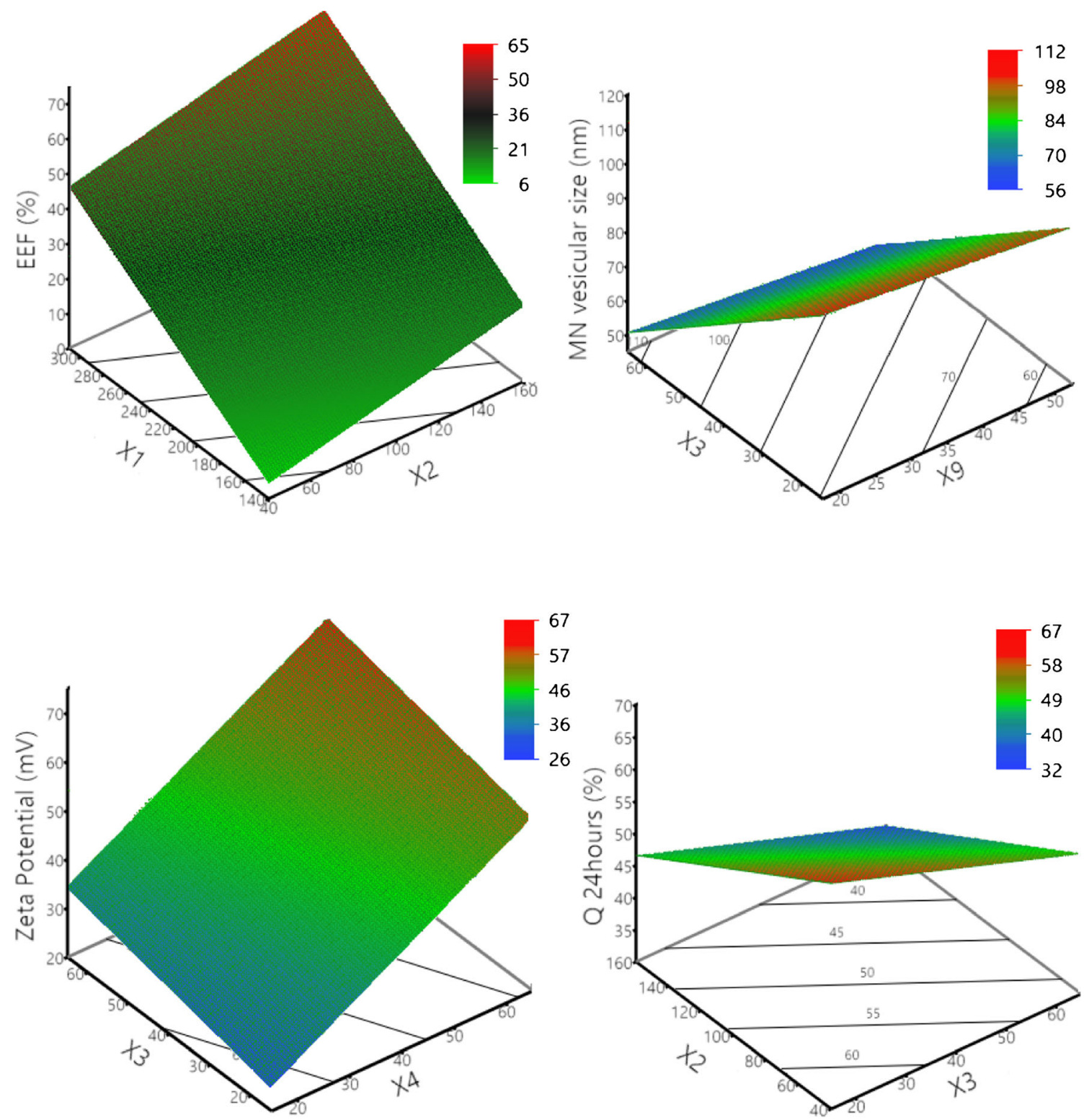

Fig. 3. Response surface and contour plots of selected significant factors on the responses. (EEF is drug entrapment efficiency; $M N$ vesicular size is the number weighted vesicular size; $Q 24 h$ is percentage of sertraline hydrochloride released after 24 h; and X1-10 are phospholipid, cholesterol, dicetyl phosphate, N-acetyl glucosamine, polyethylene glycol 4000 and sertraline hydrochloride weight loadings, methanol volume, hydration time, sonication amplitude, and sonication time, respectively)

sonication and 5 cycles of freeze-thawing, the resultant sizes and skewness values were below $150 \mathrm{~nm}$ and 0.8 , respectively (Table II). The influence of dicetyl phosphate to decrease both vesicular sizes and size heterogeneity could be attributed to its potential of not only encountering negative charges at liposomal surfaces but changing the packing structure of the liposomal lamellae as well. Compared to the longer alkyl chain of the employed phospholipid (42 carbons), the shorter alkyl chain of dicetyl phosphate (16 carbons) might stabilize the assembled lamellar structure. This effect would reduce both reassembling into smaller vesicles and fusing into larger vesicles (10). On the other hand, high surface potentials exerted by increasing dicetyl phosphate loading would expand the interlamellar aqueous phase by the electrostatic repulsion to both entrap more hydrophilic drug molecules and reduce the vesicular sizes (26). The significant and nonsignificant positive effects of PEG loading on the resultant sizes and skewness values could be attributed to the reduced electrostatic repulsion, preventing fusion and disruption of the liposomes (27). On the other hand, the significant positive and negative effect of cholesterol loading on the resultant vesicular size and skewness values, respectively, can be explained by its stabilizing action of the formed lamellae to reduce liposomal reassembling in the dispersion to smaller vesicles with narrow size distribution (28). Regarding the processing parameters, the sonication amplitude influence to significantly and nonsignificantly reduce the resultant sizes and skewness values, respectively, would be explained by the cavitation and bubble implosion which contributed to the heat energy of the liposomal dispersion (29). These effects would result in vesicular friction within the bulk dispersion from the mixing effect, and vesicular friction between the bulk dispersion with the 
stationary boundary layer adjacent to the side of the vessel. Therefore, the formulation and processing variability could affect the resultant vesicular sizes as well as lamellar structure significantly, and subsequently affects the encapsulation of Ser-HCl. The predictability of the vesicular size and size homogeneity by the model was acceptable with $p$ values of 0.0272 and 0.0249 , root mean square errors of $11.98 \mathrm{~nm}$ and 0.04 , and regression coefficients $\left(R^{2}\right)$ of 0.9547 and 0.9568 for plotting the predicted vesicular size and skewness values versus their experimental values, respectively (Fig. 2). The distribution of the residual values for both responses followed fitted normal distribution patterns with a random scattering around zero to indicate normality (Fig. 2). Moreover, the half-normal plots showed linear correlations of their experimental values and the corresponding $t$ ratios to confirm the normal distribution among the data. After neglecting the insignificant variables, the reduced linear model equations to predict both vesicular sizes and the corresponding skewness can be expressed as:

$$
\begin{aligned}
& \begin{array}{l}
\text { Vesicular } \\
\text { size }(\mathrm{nm})
\end{array}=83.92+14.9 *\left[\frac{\mathrm{X} 1-225]}{75}\right]+18.5 *\left[\frac{\mathrm{X} 2-100]}{50}\right]-13.09 *\left[\frac{[\mathrm{X} 3-40]}{20}\right]-10.2 *\left[\frac{[\mathrm{X} 9-35]}{15}\right] \\
& \text { Skewness }=0.74-0.08 *\left[\frac{[\mathrm{X} 3-40]}{20}\right]-0.04 *\left[\frac{[\mathrm{X} 4-40]}{20}\right]+0.03 *\left[\frac{\mathrm{X} 5-50]}{25}\right]+0.04 *\left[\frac{[\mathrm{X} 7-30]}{10}\right]
\end{aligned}
$$

\section{Vesicular Surface Charge}

The contribution of surface charges to stabilize the liposomal dispersion has been investigated previously to indicate the dependence of the vesicular repulsion on both the surface charge intensity and surface dipole density (30). Manciu and coworker has also demonstrated a polarization that oscillates with the distance from the vesicular surface to form a monotonically decaying average polarization when the polarizing surface is considered rough or fluctuating (31). Hence, the surface polarization formed by charged lipid and/or bulk electrolytes during hydration would have great impact on liposomal stability. In this regard, zeta potential of the proposed 15 formulations was recorded to investigate liposomal stability. Table II shows that zeta potential values varied from $7.3 \mathrm{mV}$ (F15) to $106.1 \mathrm{mV}(\mathrm{F} 4)$. The most significant factors affecting the resultant zeta potential of liposomal dispersions were phospholipid, dicetyl phosphate, and NAG loadings $(p<0.05$, Table III and Fig. 1$)$. Contour and response surface plots of Fig. 3 showed that increasing dicetyl phosphate concentration resulted in significant increase in zeta potential (Table III and Fig. 3). On the other hand, at constant loadings of dicetyl phosphate, increasing either phospholipid or NAG loadings was decreasing zeta potential of liposomal dispersions (Table III). The incorporation of dicetyl phosphate within the lipid matrix of neutral liposomes imparted negative electrophoretic mobilities. The adsorption of either positively ionized form of Ser-HCl or NAG would decrease the intensity of negative charges and change the sign to positive. These observations would indicate the effective coating of the prepared vesicles with NAG with lesser contribution by PEG. On the other hand, the negative influence of neutral phospholipid on the negatively charged vesicles could be attributed to the dilution effect of dicetyl phosphate charge intensity as more vesicles were formed. This effect could decrease the hydrodynamically counter charges in the double layer to reduce the dispersion's zeta potential (32).

Table II shows that formulations F1-F9 exhibited a zeta potential values of $>30 \mathrm{mV}$ to indicate their kinetic stabilities with minimized agglomeration and fusion phenomena due to the London dispersion forces (33). Moreover, Chonn and coworkers suggested that these high surface charges of liposomes would activate the complement system leading to a blood serum drug opsonization and subsequent phagocytosis (34). Thus, limits should be used with the incorporated loadings of dicetyl phosphate and NAG to preserve the dispersion's stability while maintaining Ser- $\mathrm{HCl}$ entrapment and surface glycosylation. The influences of other factors were minimal with $p$ values more than 0.05 ; hence, they were neglected to develop the predictability model. The developed model showed good predictability of $p=0.0101$ for zeta potential prediction with quantile-quantile correlation coefficient of 0.9732 (Fig. 2). The linear reduced model equation to predict zeta potential of the liposomal dispersion can be expressed as:

$\underset{(\mathrm{mV})}{\text { Zeta Potential }}=46.3-26.5 *\left[\frac{[\mathrm{X} 1-225]}{75}\right]+5.02 *\left[\frac{[\mathrm{X} 3-40]}{20}\right]+11.3 *\left[\frac{[\mathrm{X} 4-40]}{20}\right]$

\section{Drug Leakage}

Ser- $\mathrm{HCl}$ leakage rates from the prepared formulation were evaluated over $24 \mathrm{~h}$ and are represented in Fig. 4. Ser$\mathrm{HCl}$ slowly started to leak out of the vesicles from the first hour of leakage experiments at $37^{\circ} \mathrm{C}$. For all formulations, less than $10 \% \mathrm{Ser}-\mathrm{HCl}$ was released within $60 \mathrm{~min}$ due to the diffusion of the adsorbed drug molecules at vesicular surface, except for formula F4 that released about 30\% (Fig. 4). Hence, a constraint for the percentage drug adsorbed at liposomal surface was applied to be not more than $10 \%$. Regarding the dialysis membrane for leakage testing, it is worth noting that the employed membrane allowed diffusion equilibrium to be attained at both sides of the membrane within $1 \mathrm{~h}$ when dialysis performed for Ser-HCl aqueous solution.

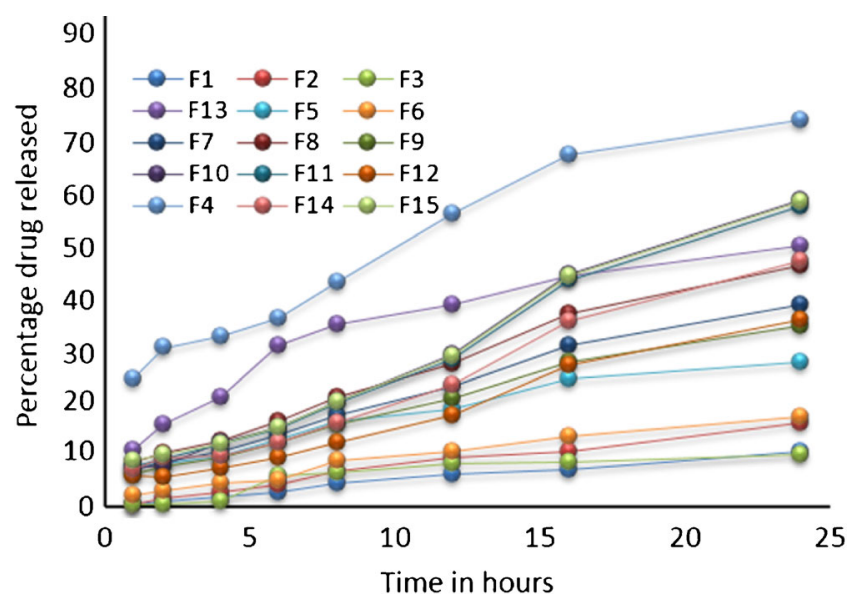

Fig. 4. Release profiles of sertraline hydrochloride from the 15 liposomal formulations using diffusion cells (dialysis membrane MWCO $20 \mathrm{kDa}$ cellulose ester, $10 \mathrm{mM}$ phosphate buffer $(\mathrm{pH} 6.8), 37^{\circ} \mathrm{C}$, $300 \mathrm{rpm}, n=3)$. Standard deviation did not exceed $5 \%$ of the release percentage at each time point 
Table IV. Values of Release Kinetic Parameters for the Prepared Liposomal Formulations

\begin{tabular}{|c|c|c|c|c|c|c|c|}
\hline \multirow[t]{2}{*}{ Batch no. } & \multicolumn{2}{|c|}{ Zero-order kinetics } & \multicolumn{2}{|c|}{ First-order kinetics } & \multicolumn{2}{|c|}{ Diffusion model } & \multirow{2}{*}{$\begin{array}{l}\text { Korsmeyer-Peppas model } \\
n\end{array}$} \\
\hline & $r$ & $k\left(\% \mathrm{~h}^{-1}\right)$ & $r$ & $k\left(\% \mathrm{~h}^{-1}\right)$ & $r$ & $k\left(\% \mathrm{~h}^{-1 / 2}\right)$ & \\
\hline $\mathrm{F} 1$ & 0.9877 & 0.56 & 0.5855 & -0.01 & 0.992 & 3.34 & -0.2397 \\
\hline $\mathrm{F} 2$ & 0.9877 & 1.50 & 0.577 & -0.02 & 0.992 & 8.74 & -0.0931 \\
\hline F3 & 0.8925 & 0.56 & 0.8984 & -0.01 & 0.9435 & 3.52 & 0.3031 \\
\hline F4 & 0.9382 & 2.10 & 0.9721 & -0.04 & 0.9852 & 13.08 & 0.4955 \\
\hline F5 & 0.9401 & 1.18 & 0.3532 & -0.02 & 0.9797 & 7.01 & 0.2359 \\
\hline F6 & 0.9768 & 0.85 & 0.3789 & -0.01 & 0.9922 & 5.03 & 0.185 \\
\hline F7 & 0.9787 & 1.81 & 0.3039 & -0.03 & 0.9904 & 10.60 & 0.332 \\
\hline F8 & 0.9787 & 2.17 & 0.2621 & -0.03 & 0.9904 & 12.72 & 0.3289 \\
\hline F9 & 0.9787 & 1.63 & 0.3212 & -0.02 & 0.9904 & 9.54 & 0.3084 \\
\hline F10 & 0.9936 & 2.96 & 0.9799 & -0.05 & 0.9645 & 17.08 & 0.6809 \\
\hline F11 & 0.9926 & 2.86 & 0.9792 & -0.05 & 0.9608 & 16.45 & 0.6461 \\
\hline F12 & 0.9905 & 1.76 & 0.9862 & -0.02 & 0.9545 & 10.09 & 0.6053 \\
\hline F13 & 0.9118 & 2.88 & 0.1458 & -0.11 & 0.957 & 17.15 & 0.4158 \\
\hline F14 & 0.9892 & 2.28 & 0.9813 & -0.04 & 0.9523 & 13.07 & 0.5895 \\
\hline F15 & 0.9909 & 2.86 & 0.9764 & -0.05 & 0.9556 & 16.42 & 0.6089 \\
\hline
\end{tabular}

Each value represents the mean of three determinations. $k$ : Kinetic constant of drug release; $r$ : coefficient of correlation; and $n$ : diffusional release exponent indicative of the operating release mechanism

This was deemed critical to exclude that dialysis step was the rate limiting step for leakage experiments, hence sink condition was maintained. Two release points, namely Q2h and Q24h (percentages Ser-HCl leaked after 2 and 24 h, respectively), were nominated to understand the factors influences in retarding Ser- $\mathrm{HCl}$ release from the prepared vesicles. The obtained results showed that Q2h and Q24h ranged from $0.8 \%(\mathrm{~F} 12)$ to $32.5 \%(\mathrm{~F} 4)$ and from $12.5 \%(\mathrm{~F} 12)$ to $93.7 \%$ (F4), respectively (Table II). Regarding the formulation variables, Fig. 1 and Table III demonstrate that phospholipid, cholesterol, dicetyl phosphate, and NAG loading were significant $(p<0.05)$ for their influences on both Q2h and Q24h with maximum effect for phospholipid concentration. On the other hand, sonication amplitude and time were the significant processing variables to affect Ser- $\mathrm{HCl}$ leakage.

The obtained results revealed inverse relationships between the significant formulation variables and both leakage responses (Table III and Fig. 3). The accelerated initial Ser$\mathrm{HCl}$ leakage caused by decreasing cholesterol concentration within the lipid pool could be attributed to its effect on packing intensity of the lamellar components. In particular, it might not only reduce the density of the phospholipid head groups at the interfacial region of the liposomal lamellae but also increase the packing intensity of the phospholipid hydrophobic alkyl chains in the middle region of lamellae to retard drug leakage (35). The negative effect of dicetyl phosphate on both leakage responses could be attributed to its ionic interaction with the ionized drug molecules at liposomal surface (21). NAG showed also a negative effect on both Q2h and Q24h due to the electrostatic repulsion between the positively charged NAG ammonium salt and drug molecules at liposomal surface. The positive effects of sonication parameters on both Q2h and Q24h were reflection of their effects on vesicular sizes and $\mathrm{Ser}-\mathrm{HCl}$ entrapment. The negative influence of the sonication amplitude to decrease drug encapsulation resulted in a modulation of surface distribution of drug molecules to accelerate both the initial and retarded release. Moreover, increasing the sonication parameters resulted in decreasing vesicular sizes to increase lamellar diffusion areas for higher Ser-HCl leakage. The developed prediction models of both responses showed good predictabilities with $p$ values of 0.0153 and 0.0027 for Q2h and Q24h, respectively. Quantile-quantile plots in Fig. 2 showed correlation coefficients of 0.9666 and 0.9862 and root mean square errors of 3.1 and 5.4\% for Q2h and Q24h, respectively. Moreover, normality among the leakage data was evident from the half-normal plots. The linear reduced model equations to predict these leakage parameters are given below:

$$
\begin{array}{r}
\text { Q2h }(\%)=11.09-4.4 *\left[\frac{\mathrm{X} 1-225]}{75}\right]-5.33 *\left[\frac{[\mathrm{X} 2-100]}{50}\right]-3.1 *\left[\frac{\mathrm{X} 3-40]}{20}\right] \\
-3.9 *\left[\frac{[\mathrm{X} 4-40]}{20}\right]+3.2 *\left[\frac{[\mathrm{X} 9-35]}{15}\right] \\
\begin{array}{r}
\text { Q24h }(\%)=49.1-21.3 *\left[\frac{[\mathrm{X} 1-225]}{75}\right]-9.2 *\left[\frac{[\mathrm{X} 2-100]}{50}\right]-5.8 *\left[\frac{[\mathrm{X} 3-40]}{20}\right] \\
-5.9 *\left[\frac{[\mathrm{X} 4-40]}{20}\right]+7.5 *\left[\frac{\mathrm{X} 9-35]}{15}\right]
\end{array}
\end{array}
$$

The Ser-HCl release was best fitted using a linear regression model against the square root of time, which hints at a diffusion-controlled process (Table IV). For formulations F10, F11, F12, F14, and F15, the drug release constants obtained for the zero-order drug release kinetics suggested that liposomes acted as reservoir systems for a continuous $\mathrm{Ser}-\mathrm{HCl}$ delivery. The literature provides evidence that for liposomal formulations, the diffusion model based on the goodness-of-fit test endures to be the most appropriate model to describe the kinetics of drug release, when compared to zero-order and first-order (36). Furthermore, it enables an understanding of the quantitative deviation of the proposed formulation from the diffusion-controlled ideal Higuchi model. The plots' data showed good linearity for the glycosylated liposomes. 
Table V. Summary of ANOVA Testing for Evaluating the Significance of the Model in Portions

\begin{tabular}{|c|c|c|c|c|c|c|c|c|}
\hline \multirow{2}{*}{\multicolumn{2}{|c|}{ Responses }} & \multicolumn{5}{|c|}{ ANOVA parameters } & \multicolumn{2}{|c|}{ Lack of fit parameters } \\
\hline & & $\mathrm{DF}$ & SS & MS & $F$ ratio & Prob $>F$ & $\mathrm{DF}$ & Prob $>F$ \\
\hline \multicolumn{2}{|c|}{ Entrapment efficiency (\%) } & 10 & $8.8 \mathrm{E}+3$ & $8.8 \mathrm{E}+2$ & 16.55 & 0.0078 & 2 & 0.6992 \\
\hline \multicolumn{2}{|c|}{ Number weighted vesicular size (nm) } & 10 & $1.2 \mathrm{E}+4$ & $1.2 \mathrm{E}+3$ & 8.44 & 0.0272 & 2 & 0.6019 \\
\hline \multicolumn{2}{|l|}{ Skewness } & 10 & $1.9 \mathrm{E}-1$ & $1.9 \mathrm{E}-2$ & 8.87 & 0.0249 & 2 & 0.0613 \\
\hline \multicolumn{2}{|c|}{ Zeta potential (mV) } & 10 & $1.2 \mathrm{E}+4$ & $1.2 \mathrm{E}+3$ & 14.53 & 0.0101 & 2 & 0.0591 \\
\hline \multirow[t]{2}{*}{ Release data ${ }^{a}$} & Q2h (\%) & 10 & $1.1 \mathrm{E}+3$ & $1.1 \mathrm{E}+2$ & 11.59 & 0.0153 & 2 & 0.1427 \\
\hline & Q24h (\%) & 10 & $8.5 \mathrm{E}+3$ & $8.5 \mathrm{E}+2$ & 28.66 & 0.0027 & 2 & 0.9431 \\
\hline
\end{tabular}

$D F$ degree of freedom, $S S$ sum of squares, $M S$ mean of squares

${ }^{a} \mathrm{Q} 2 \mathrm{~h}$ and Q24h are percentages of sertraline hydrochloride released after 2 and $24 \mathrm{~h}$, respectively

\section{Analysis of Variance}

Plotting the actual responses' values versus the corresponding predicted values gave linear relationships with $R^{2}$ values more than 0.81 (Fig. 2). For all the developed prediction models, root mean square error values were below $7 \%$ of the estimated responses' values. Moreover, the residuals versus predicted values plots demonstrated scattered patterns about zero with linear half-normal plots to not only state the normality but exclude outliers or any consistent variance as well. This would indicate that validity of ANOVA results was evidenced (Fig. 2). At $p$ value of 0.05 for confidence limit, degrees of freedom of 10 , sum of squares of $8.8 \times 10^{3}, 1.2 \times 10^{4}, 1.9 \times 10^{-1}, 1.2 \times 10^{4}, 1.1 \times 10^{3}$, and $8.5 \times 10^{3}$, with mean squares of $8.8 \times 10^{2}, 1.2 \times 10^{3}$, $1.9 \times 10^{-2}, 1.2 \times 10^{3}, 1.1 \times 10^{2}$, and $8.5 \times 10^{2}$, were recorder for $\mathrm{EE}$, number weighted vesicular size, skewness, zeta potential, Q2h, and Q24h, respectively (Table V). Values of the root mean squared error (RMSE), the $F$ ratio, the Prob $>F$ value, $R^{2}$, the adjusted correlation coefficient (Adj$R^{2}$ ), and the lack of fit $F$ ratio were used to assess the predictability of the constructed models. Being in good agreement with the corresponding Adj- $R^{2}$ values (0.9174, $0.8416,0.8489,0.9062,0.8831$, and 0.9518$)$, the $R^{2}$ values of $0.9764,0.9547,0.9568,0.9732,0.9666$, and 0.9862 for $\mathrm{EE}$, number weighted vesicular size, skewness, zeta potential, Q2h, and Q24h, respectively, were obtained to indicate a good fit with more than $95 \%$ of variation in the investigated responses explained by the fitted model (Fig. 2). This was confirmed by the $F$ ratios and Prob $>F$ values: the formers (16.55, 8.44, 8.87, 14.53, 11.59, and 28.66 for EE, number weighted vesicular size, skewness, zeta potential, Q2h, and Q24h, respectively) were more than their critical values, while the latters were as low as $0.0078,0.0272,0.0249$, $0.0101,0.0153$, and 0.0027 for EE, number weighted vesicular size, skewness, zeta potential, Q2h, and Q24h, respectively (Table $\mathrm{V}$ ). The lacks of fit $F$ ratio values were also below their respective critical values to state the nonsignificance lack of fit for all responses. Therefore, the results of the ANOVA models revealed the validity of the developed prediction models within the experimental design space; hence, an optimization design with a generalized desirability function could be applied to the most significant variables with high degree of accuracy to finally optimize the liposomal formulation.

\section{Optimization and Desirability Function}

Having studied the effects of the investigated factors on the responses, the optimized levels of these factors were determined using generalized desirability function to maximize Ser-HCl EE and zeta potential while minimizing the vesicular size, skewness, Q2h, and Q24h. Applying each individualized desirability function along with these constraints on the responses resulted in predicted values of $32.6 \mathrm{~nm}, 0.23,45.4 \%$, $2.4 \%, 11.7 \%$, and $17.8 \mathrm{mV}$ for number weighted vesicular size, skewness, Ser-HCl EE, Q2h, Q24h, and zeta potential, respectively, at phospholipid, cholesterol, dicetyl phosphate, NAG, PEG, drug amounts, methanol percent in chloroform, hydration time, sonication amplitude, and time of $300 \mathrm{mg}, 50 \mathrm{mg}$, $60 \mathrm{mg}, 60 \mathrm{mg}, 50.1 \mathrm{mg}, 50 \mathrm{mg}, 40 \%, 10 \mathrm{~min}, 50 \%$, and $30 \mathrm{~s}$, respectively. Under these experimental conditions, all the responses' constraints implemented on the individual functions were applied and overall and individual desirability functions of more than $85 \%$ were achieved. As a confirmation process, a fresh formulation was prepared with the optimized values of the independent variables that yielded $35.1 \mathrm{~nm}, 0.25,47.2 \%$, $2.6 \%, 10.9 \%$, and $19.2 \mathrm{mV}$ for number weighted vesicular size, skewness, Ser-HCl EE, Q2h, Q24h, and zeta potential, respectively. The observed values were not significantly different $(p<0.05)$ from the predicted values with standardized residuals for each response not exceeding $5 \%$ of the nominal value demonstrating the feasibility of the developed model to understand the critical characteristics of Ser-HCl-loaded glycosylated and pegylated liposomes.

\section{Solid-State Characterization}

Figure 5 demonstrates the shape and surface properties of the optimized glycosylated liposomes. SEM image shows the spherical nature of intact liposomes with approximated vesicular size range of $38 \mathrm{~nm}$ and narrow size distribution. This observation was in a good agreement with those obtained by light scattering that unveiled a vesicular size of $35.1 \mathrm{~nm}$ and skewness value of 0.23 .

FTIR and DSC analysis of freeze dried optimized liposomal formulation were performed to understand the interaction among its components. FTIR spectrum of $\mathrm{Ser}-\mathrm{HCl}$ powder in Fig. 5 shows stretching aliphatic of aromatic C-H absorption band at $2812 \mathrm{~cm}^{-1}, \mathrm{C}=\mathrm{C}$ vibrations of the aromatic groups at 1417 and $1147 \mathrm{~cm}^{-1}, \mathrm{~N}^{+}-\mathrm{H}$ stretching vibration at 

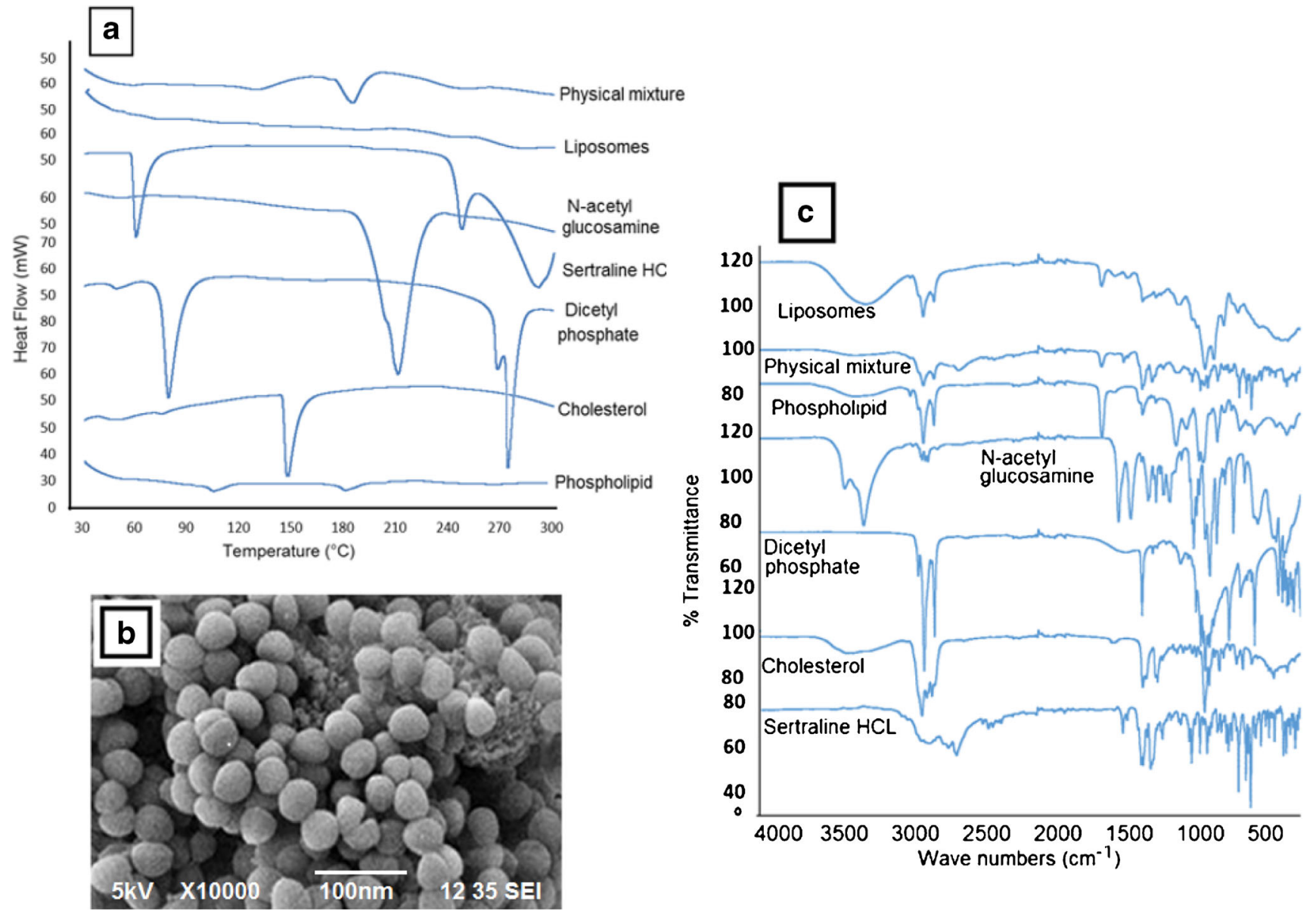

Fig. 5. DSC (a), SEM (b), and FTIR (c) analysis of the optimized liposomal formulation

2472-2704 $\mathrm{cm}^{-1}$, and C-Cl stretching deformation band of aromatic substitution at $842 \mathrm{~cm}^{-1}$. FTIR spectrum of phospholipid showed a main vibrational stretch at $1645 \mathrm{~cm}^{-1}$ due to $\mathrm{C}=\mathrm{O}$ vibration in addition to a weak aliphatic $\mathrm{C}-\mathrm{H}$ stretches at 2942-2836 $\mathrm{cm}^{-1}$. Cholesterol spectrum exhibited a main characteristic broad stretch at $3214-2823 \mathrm{~cm}^{-1}$ due to $\mathrm{O}-\mathrm{H}$ group. Dicetyl phosphate showed also the broad vibrational band at $3155-2825 \mathrm{~cm}^{-1}$ due to $\mathrm{O}-\mathrm{H}$ groups of phosphate salt in addition to $\mathrm{CH}_{2}$ bending band at $1360 \mathrm{~cm}^{-1}$. NAG spectrum exhibited the aliphatic $\mathrm{C}-\mathrm{H}$ stretches at 2981 and $2862 \mathrm{~cm}^{-1}$, a sharp stretch of $\mathrm{C}-\mathrm{N}$ at $1373 \mathrm{~cm}^{-1}$, and $\mathrm{NH}_{2}$ bending vibration at $645 \mathrm{~cm}^{-1}$ (Fig. 5). Physical mixture of the individual components displayed superposition of absorption bands for all ingredients to indicate absence of any interactions among Ser$\mathrm{HCl}$ and any of these ingredients. FTIR spectrum of the optimized liposomal powder showed both disappearance of the Ser- $\mathrm{HCl} \mathrm{C}-\mathrm{H}$ absorption band and broadening of absorption band of aromatic groups (Fig. 5). This shift might be attributed to the interaction between the functional group of $\mathrm{Ser}-\mathrm{HCl}$ and the carbonyl and hydroxyl groups of lipid matrix. Having these results along with significant effect of dicetyl phosphate to enhance Ser-HCl entrapment, it might confirm the significant association of the drug and dicetyl phosphate through hydrogen bonding.

DSC analysis was also conducted to explore the interaction within the liposomal formulation by the action of increasing the temperature (Fig. 5). Ser-HCl, NAG and dicetyl phosphate thermograms showed melting endotherms at 68,211 , and $77^{\circ} \mathrm{C}$, respectively. This melting endotherm is in agreement with that reported by $\mathrm{He}$ and coworkers $\left(66.5 \pm 0.5^{\circ} \mathrm{C}\right)$ for $\mathrm{Ser}-\mathrm{HCl}$ enantiomer (37). Another endotherm was also detected for dicetyl phosphate at $275^{\circ} \mathrm{C}$ due to its decomposition (38). Cholesterol showed a sharp melting transition at $150^{\circ} \mathrm{C}$. Phospholipid thermogram showed weak broad transitions at 117 and $176^{\circ} \mathrm{C}$ due to the loss of the adsorbed water of hydration and its melting, respectively (10). In physical mixture thermogram, the endothermic transition of the Ser- $\mathrm{HCl}$ was shifted to $65.9^{\circ} \mathrm{C}$ (Fig. 5), and this can be attributed to the interaction between the pure components in the physical mixture by the action of temperature increase. Endothermic peaks from 153 to $196^{\circ} \mathrm{C}$ were also detected in the DSC thermogram of physical mixture, which could be described by dehydration events and interaction between Ser$\mathrm{HCl}$ and lipid matrix by increasing the temperature. The drug's endotherm observed at $65.9^{\circ} \mathrm{C}$ was completely missing in the optimized liposomal formulation (Fig. 5). Moreover, its thermogram was missing most the transition of the corresponding physical mixture to indicate the significant modification of the bilayer fluidity by dicetyl phosphate and $\mathrm{Ser}-\mathrm{HCl}$ association.

\section{In Vitro BBB Transport Model}

The endothelialpolyoma middle $\mathrm{T}$ antigen transformed cell lines were employed as in vitro BBB model to evaluate the transendothelial ability of the proposed optimized 
glycosylated liposomal formulation. Measures of TEER were primarily utilized to assess tight junctions' integrity of monolayers prior and after transport studies. The obtained results showed that TEER values were varied between 150 and $180 \Omega / \mathrm{cm}^{2}$ to indicate that monolayer's tightness was robust and controlled (39). The cytotoxicity of the optimized liposomal formulations toward endothelialpolyoma middle $\mathrm{T}$ antigen transformed cells at two different Ser-HCl loadings of concentrations of 10 and $20 \mu \mathrm{g} / \mathrm{mL}$ was performed to evaluate the percentage of the cell viability. The result obtained (Fig. 6) showed that at higher concentration of the formulations yielded more than $90 \%$ viable cells. Below the concentration of $20 \mu \mathrm{g} / \mathrm{mL}$, appreciable amount of cell viability was observed suggesting the employed concentrations were nontoxic to the cells. Figure 6 shows the rank of accumulated percentage Ser$\mathrm{HCl}$ permeated across the in vitro $\mathrm{BBB}$ over a period of $16 \mathrm{~h}$. The percentages Ser-HCl permeated after $16 \mathrm{~h}$ were $14.2 \% \pm 2.8$ for nonglycosylated Ser-HCl-loaded optimized liposomes and $71.2 \% \pm 14.6$ for glycosylated Ser-HCl-loaded optimized vesicles. This significant enhancement $(p<0.05)$ of Ser-HCl permeation would indicate the effectiveness of glycosylation in the transendothelial process of brain-targeting liposomes. In particular, GLUT1 expression at the BBB facilitated this transport across the $\mathrm{BBB}$. Compared to the Ser-HCl solution (control) of the same concentration, it can be observed from Fig. 6 that the optimized formulation equivalent to $20 \mu \mathrm{g} / \mathrm{mL}$ Ser-HCl loading resulted in nonsignificant higher cytotoxicity than $10 \mu \mathrm{g} / \mathrm{mL}$ Ser- $\mathrm{HCl}$ loading. Unfortunately, this fair transport enhancement at $20 \mu \mathrm{g} / \mathrm{mL}$ Ser- $\mathrm{HCl}$ loading might be associated with making higher volume of the liposomal formulation less suitable as brain-targeting systems.

As a confirmation of the transport mechanism, inhibition assay was then performed by pre-incubation with either cytochalasin B or phenobarbital. Figure 6 demonstrates that the transendothelial ability of the optimized glycosylated liposomes significantly decreased after this pre-incubation. Moreover, treatment with cytochalasin $\mathrm{B}$ led to a greater reduction of the transendothelial ability than phenobarbital. For example, the percentages $\mathrm{Ser}-\mathrm{HCl}$ permeated after $16 \mathrm{~h}$ were $9.8 \% \pm 4.9$ and $26.3 \% \pm 5.2$ for cytochalasin $\mathrm{B}$ and phenobarbital pre-incubation, respectively. This result would be attributed to cytochalasin B affinity as a ligand to bind to GLUT1, hence inhibited glucose transport across the endothelial cells (40). Dick and coworker observed that the labeling density with cytochalasin B was slightly lower in the cerebellar than in cerebral microvessels (41). Hence, this observation would suggest that the proposed glycosylated liposomes showed an ability to target the cerebellar due to its higher density of GLUT1 and higher glucose utilization. On the other hand, phenobarbital might interact directly with GLUT1 protein, hence inhibiting the intrinsic activity of GLUT1 (42). Prominently, other studies suggested that the maximal velocity for glucose transport across BBB was reduced by phenobarbital due to either its direct effect on GLUT1 in the endothelial cells of cerebral microvessels or a decrease in the number of functional GLUT1 transporters (43). It is worth also noting that no significant reductions in TEER values were observed in any group during this study to indicate that the both the preincubation with the inhibitors and sertraline transport did not disrupt the BBB barrier properties. Similar observations were reported by other researchers that glycosylated liposomes not only could promote the transendothelial penetration but also could be accumulated in the brain with a distinct spatiotemporal pattern (44).

\section{C6 Glioma Cellular Uptake}

Of the four different treatments, the internalization of the optimized glycosylated liposomes was the most noticeable (Fig. 7a, b). The mean fluorescent intensity uptake of optimized glycosylated liposomes by C6 glioma cells was significant $(p<0.05)$ compared with the optimized nonglycosylated formulation (Fig. 7a, b). The obtained results from the C6 glioma cellular uptake assay using flow cytometry demonstrated that the mean fluorescence intensities of Rho were 230 \pm 26 FUs for free Rho dye, $643 \pm 43$ FUs for optimized nonglycosylated formulation, $2873 \pm 152$ FUs for optimized glycosylated liposomes, and $1183 \pm 93$ FUs for optimized glycosylated liposomes after treatment with the inhibitor. To further evaluate the capacity of C6 glioma cells to uptake different liposomal formulations, time-lapse live cell imaging was employed. The images of the uptake of different

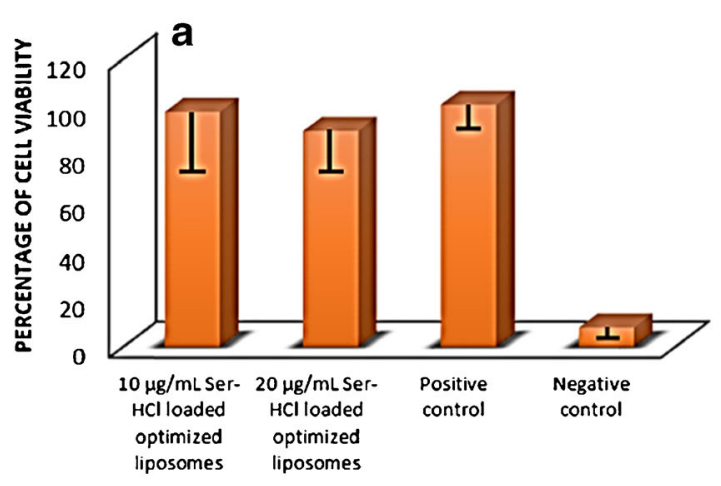

- Nonglycosylated liposomes 口Glycosylated liposomes + Cytochalasin B a Sertraline solution $(20 \mu \mathrm{g} / \mathrm{mL})$

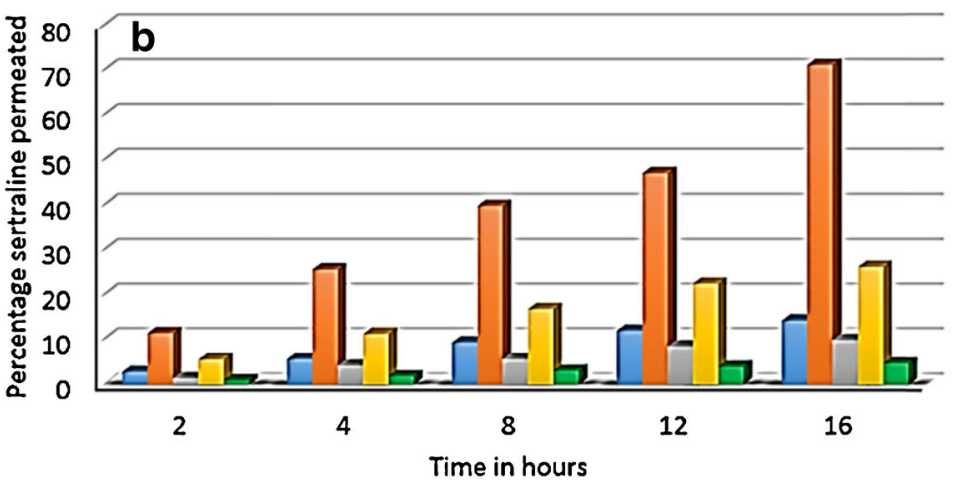

Fig. 6. a Percentage of rat endothelialpolyoma middle T antigen transformed cell viability for the optimized formulation at 10 and $20 \mu \mathrm{g} / \mathrm{mL}$ Ser$\mathrm{HCl}$ loadings (each data point represents the mean $\pm \mathrm{SD}$ of four determinations) and b transendothelial permeability of the optimized formulation of Ser-HCl-loaded glycosylated liposomes through an in vitro BBB model (the data represent cumulative percentage Ser-HCl permeated at specified time-points of three replicates with standard deviation values did not exceed $8 \%$ of the recorded percentages) 
preparations from $0 \mathrm{~s}$ to $30 \mathrm{~min}$ are shown in Fig. 7c. The timelapse live cell imaging showed that although C6 glioma cells could uptake all formulations, the uptake ability of the optimized glycosylated liposomes was the most significant compared with other treatments. The fluorescence intensity increased from 386 to 512 FUs for optimized glycosylated liposomes, from 386 to 467 FUs for optimized nonglycosylated formulation, and from 386 to 439 FUs for optimized glycosylated liposomes after treatment with the inhibitor (Fig. 7c). Imaging and data analysis demonstrated that the optimized nonglycosylated formulation slowly uptaken by C6 glioma cells. On the other hand, there was a rapid accumulation of the optimized glycosylated liposomes in the glioma cells at the 4-min time point. Moreover, the uptake of optimized glycosylated liposomes was significantly inhibited by phenobarbital, resulting in an uptake profile comparable to that for optimized nonglycosylated formulation.
Transporters within the BBB are membrane-restricted structures and facilitate transcytosis to transport nutrients such as glucose, glycosylated structures, amino acids, and purine bases to the brain (1). Adsorptive-mediated endocytosis is instigated by the association of polycationic structures to negatively charged plasma membrane (45). Since glioma cells express GLUT1 and GLUT3 transporters, the obtained transport and uptake results would indicate that the uptake of the optimized glycosylated liposomes was mediated by both transcytosis and adsorptive endocytosis (46). On the other hand, the uptake of optimized nonglycosylated formulation might occur only by an adsorptive endocytosis process (47). Consequently, the two pathways for liposomal uptake by C6 glioma cells differ mechanistically. The transcytosis pathway was a rapid and short route; however, the adsorptive endocytosis pathway was a slow and long route. Additionally, different studies by other researchers have demonstrated that
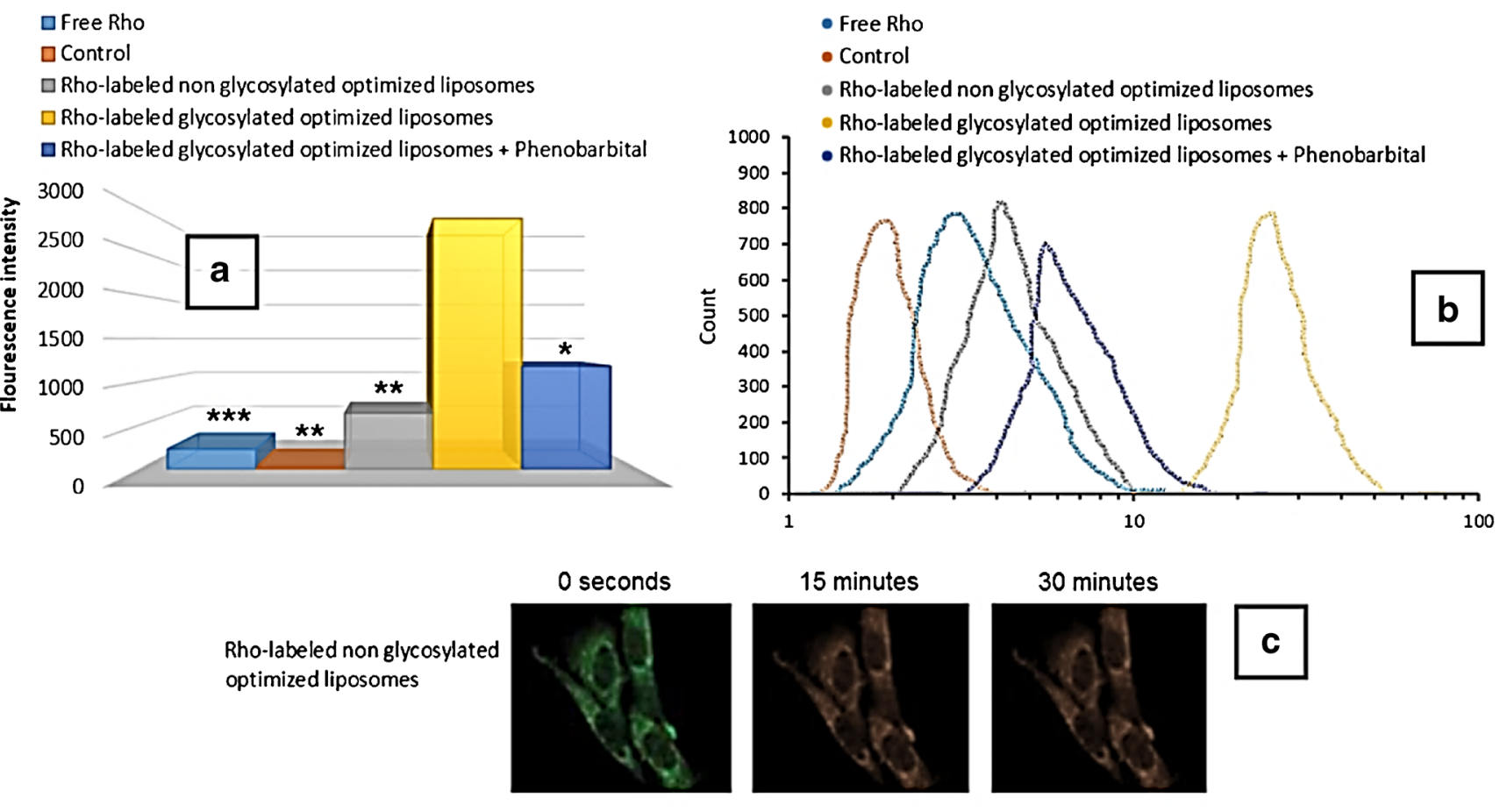

Rho-labeled glycosylated
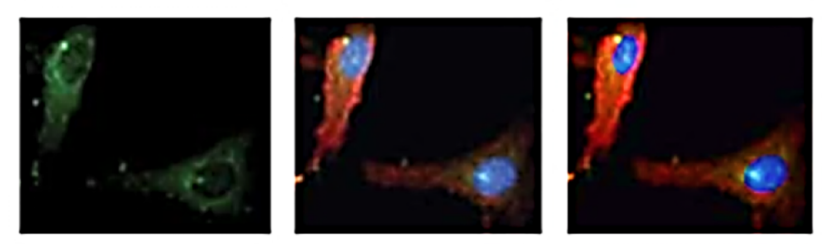

Rho-labeled glycosylated
optimized liposomes
+ Phenobarbital
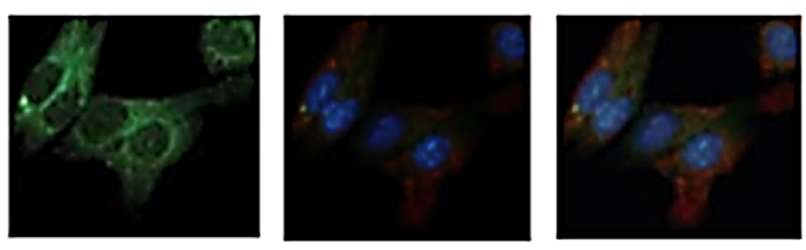

Fig. 7. Drug uptake and distribution in C6 glioma cells following the administration of the various Ser-HCl-loaded Rho-labeled optimized glycosylated liposomes using FACS flow cytometry assay. a Statistical analysis of fluorescence intensity of each preparation with data presented as the mean $\pm \mathrm{SD}(n=3)$. $* p<0.05$, ** $p<0.01$, *** $p<0.001$ versus Rho-labeled glycosylated optimized liposomes. b Uptake assay. c Fluorescence photographs of C6 glioma cells (blue, BisBenzimide H 33258 stained nucleus; green, DiO stained cell membrane; red, Rholabeled liposomes) from $0 \mathrm{~s}$ to $30 \mathrm{~min}$ of incubation with Rho-labeled optimized liposomal formulations 
phenobarbital can interact then inhibit the intrinsic activity of GLUT1 $(43,44)$. Hence, in the current investigation, the synchronous transcytosis route mediated by glucose transporters was significantly inhibited by phenobarbital. Therefore, the rapid uptake of optimized glycosylated liposomes might be described by the role of GLUT1 in the transport process.

\section{CONCLUSION}

Through QbD paradigm, an integrated screening study based on Plackett-Burman design was adopted in the current study to understand the performance of Ser-HCl-loaded pegylated and glycosylated liposomes as a promising braintargeting vector. The obtained results demonstrated the development of specialized lipid matrix by the inclusion of dicetyl phosphate and NAG within the phospholipid lamellae. Dicetyl phosphate, NAG and sonication parameters were the most significant variables influencing Ser-HCl EE, leakage and liposomal sizes. As demonstrated by the compatibility studies, a remarkable interaction was found between the drug and dicetyl phosphate to modulate the entrapment and leakage process. In addition, the proposed vectors showed a promising BBB transport capacity by GLUT1 that could be inhibited significantly by cytochalasin B and phenobarbital. Using C6 glioma cell model, flow cytometry and time-lapse live cell imaging demonstrated that optimized glycosylated liposomes can be transported through BBB by classical endocytosis, as well as by specific transcytosis. Further scale-up investigations and biologicaltargeting assessment are in progress.

\section{REFERENCES}

1. Dinda SC, Pattnaik G. Nanobiotechnology-based drug delivery in brain targeting. Curr Pharm Biotechnol. 2013;14(15):1264-74.

2. Fukuta T, Ishii T, Asai T, Nakamura G, Takeuchi Y, Sato A, et al. Real-time trafficking of PEGylated liposomes in the rodent focal brain ischemia analyzed by positron emission tomography. Artif Organs. 2014:38(8):662-6.

3. Rip J, Chen L, Hartman R, van den Heuvel A, Reijerkerk A, van Kregten J, et al. Glutathione PEGylated liposomes: pharmacokinetics and delivery of cargo across the blood-brain barrier in rats. J Drug Target. 2014;22(5):460-7.

4. Mauceri A, Borocci S, Galantini L, Giansanti L, Mancini G, Martino A, et al. Recognition of concanavalin A by cationic glucosylated liposomes. Langmuir ACS J Surf Colloids. 2014:30(38):11301-6.

5. Shestov AA, Emir UE, Kumar A, Henry PG, Seaquist ER, Oz G. Simultaneous measurement of glucose transport and utilization in the human brain. Am J Physiol Endocrinol Metab. 2011:301(5):E1040-9.

6. Farrell CL, Pardridge WM. Blood-brain barrier glucose transporter is asymmetrically distributed on brain capillary endothelial lumenal and ablumenal membranes: an electron microscopic immunogold study. Proc Natl Acad Sci U S A. 1991;88(13):5779-83.

7. Klepper J, Voit T. Facilitated glucose transporter protein type 1 (GLUT1) deficiency syndrome: impaired glucose transport into brain- a review. Eur J Pediatr. 2002;161(6):295-304.

8. Cornford EM, Gee MN, Swartz BE, Mandelkern MA, Blahd WH, Landaw EM, et al. Dynamic [18F]fluorodeoxyglucose positron emission tomography and hypometabolic zones in seizures: reduced capillary influx. Ann Neurol. 1998;43(6):801-8.

9. Cremer JE. Substrate utilization and brain development. J Cereb Blood Flow Metab. 1982;2(4):394-407.

10. Kamal N, Cutie AJ, Habib MJ, Zidan AS. QbD approach to investigate product and process variabilities for brain targeting liposomes. J Liposome Res. 2014;13:1-16.
11. Qin Y, Fan W, Chen H, Yao N, Tang W, Tang J, et al. In vitro and in vivo investigation of glucose-mediated brain-targeting liposomes. J Drug Target. 2010;18(7):536-49.

12. Xie F, Yao N, Qin Y, Zhang Q, Chen H, Yuan M, et al. Investigation of glucose-modified liposomes using polyethylene glycols with different chain lengths as the linkers for brain targeting. Int J Nanomedicine. 2012;7:163-75.

13. Kilts CD. Potential new drug delivery systems for antidepressants: an overview. J Clin Psychiatry. 2003;64 Suppl 18:31-3.

14. DeVane CL, Liston HL, Markowitz JS. Clinical pharmacokinetics of sertraline. Clin Pharmacokinet. 2002;41(15):1247-66.

15. Mandrioli R, Mercolini L, Raggi MA. Evaluation of the pharmacokinetics, safety and clinical efficacy of sertraline used to treat social anxiety. Expert Opin Drug Metab Toxicol. 2013;9(11):1495-505.

16. O'Brien FE, Dinan TG, Griffin BT, Cryan JF. Interactions between antidepressants and P-glycoprotein at the blood-brain barrier: clinical significance of in vitro and in vivo findings. $\mathrm{Br} \mathrm{J}$ Pharmacol. 2012;165(2):289-312.

17. $\mathrm{Xu} \mathrm{X}$, Khan MA, Burgess DJ. A quality by design (QbD) case study on liposomes containing hydrophilic API: II. Screening of critical variables, and establishment of design space at laboratory scale. Int J Pharm. 2012;423(2):543-53.

18. Béduneau A, Hindré F, Clavreul A, Leroux J-C, Saulnier P, Benoit J-P. Brain targeting using novel lipid nanovectors. J Control Release. 2008;126(1):44-9.

19. Das PK, Murray GJ, Zirzow GC, Brady RO, Barranger JA. Lectin-specific targeting of $\beta$-glucocerebrosidase to different liver cells via glycosylated liposomes. Biochem Med. 1985;33(1):12431.

20. Xu X, Khan MA, Burgess DJ. A quality by design (QbD) case study on liposomes containing hydrophilic API: I. Formulation, processing design and risk assessment. Int J Pharm. 2011;419(12):52-9.

21. El-Nesr OH, Yahiya SA, El-Gazayerly ON. Effect of formulation design and freeze-drying on properties of fluconazole multilamellar liposomes. Saudi Pharm J. 2010;18(4):217-24.

22. Jeon HS, Seo JE, Kim MS, Kang MH, Oh DH, Jeon SO, et al. A retinyl palmitate-loaded solid lipid nanoparticle system: effect of surface modification with dicetyl phosphate on skin permeation in vitro and anti-wrinkle effect in vivo. Int J Pharm. 2013;452(12):311-20.

23. Magin RL, Niesman MR. Temperature-dependent permeability of large unilamellar liposomes. Chem Phys Lipids. 1984;34(3):245-56.

24. Huang SL, MacDonald RC. Acoustically active liposomes for drug encapsulation and ultrasound-triggered release. Biochim Biophys Acta. 2004;1665(1-2):134-41.

25. Pencer J, White GF, Hallett FR. Osmotically induced shape changes of large unilamellar vesicles measured by dynamic light scattering. Biophys J. 2001;81(5):2716-28.

26. Yamaguchi T. Lipid microspheres as drug carriers: a pharmaceutical point of view. Adv Drug Deliv Rev. 1996;20(2-3):117-30.

27. Kim JY, Kim JK, Park JS, Byun Y, Kim CK. The use of PEGylated liposomes to prolong circulation lifetimes of tissue plasminogen activator. Biomaterials. 2009;30(29):5751-6.

28. Socaciu C, Jessel R, Diehl HA. Competitive carotenoid and cholesterol incorporation into liposomes: effects on membrane phase transition, fluidity, polarity and anisotropy. Chem Phys Lipids. 2000;106(1):79-88.

29. Silva R, Ferreira H, Little C, Cavaco-Paulo A. Effect of ultrasound parameters for unilamellar liposome preparation. Ultrason Sonochem. 2010;17(3):628-32.

30. Sabin J, Prieto G, Ruso JM, Hidalgo-Alvarez R, Sarmiento F. Size and stability of liposomes: a possible role of hydration and osmotic forces. Eur Phys J E Soft Matter. 2006;20(4):401-8.

31. Manciu M, Ruckenstein E. Oscillatory and monotonic polarization. The polarization contribution to the hydration force. Langmuir. 2001;17(24):7582-92.

32. Matsumura H, Verbich SV, Dimitrova MN. Surface conductivity of counter ions on protein-adsorbed lipid liposomes. Colloids Surf A Physicochem Eng Asp. 2001;192(1-3):331-6.

33. Casals E, Galan AM, Escolar G, Gallardo M, Estelrich J. Physical stability of liposomes bearing hemostatic activity. Chem Phys Lipids. 2003;125(2):139-46. 
34. Chonn A, Cullis PR, Devine DV. The role of surface charge in the activation of the classical and alternative pathways of complement by liposomes. J Immunol. 1991;146(12):4234-41.

35. Alinchenko MG, Voloshin VP, Medvedev NN, Mezei M, Partay L, Jedlovszky P. Effect of cholesterol on the properties of phospholipid membranes. 4. Interatomic voids. J Phys Chem B. 2005;109(34):16490-502.

36. Haidar ZS, Hamdy RC, Tabrizian M. Protein release kinetics for core-shell hybrid nanoparticles based on the layer-by-layer assembly of alginate and chitosan on liposomes. Biomaterials. 2008;29(9):1207-15.

37. He Q, Rohani S, Zhu J, Gomaa H. Sertraline racemate and enantiomer: solid-state characterization, binary phase diagram, and crystal structures. Cryst Growth Des. 2010;10(4):1633-45.

38. Manosroi A, Podjanasoonthon K, Manosroi J. Development of novel topical tranexamic acid liposome formulations. Int J Pharm. 2002;235(1-2):61-70.

39. Koto T, Takubo K, Ishida S, Shinoda H, Inoue M, Tsubota K, et al. Hypoxia disrupts the barrier function of neural blood vessels through changes in the expression of Claudin-5 in endothelial cells. Am J Pathol. 2007;170(4):1389-97.

40. Dick AP, Harik SI, Klip A, Walker DM. Identification and characterization of the glucose transporter of the blood-brain barrier by cytochalasin $\mathrm{B}$ binding and immunological reactivity. Proc Natl Acad Sci U S A. 1984;81(22):7233-7.

41. Dick AP, Harik SI. Distribution of the glucose transporter in the mammalian brain. J Neurochem. 1986;46(5):1406-11.

42. Gjedde A, Rasmussen M. Pentobarbital anesthesia reduces blood-brain glucose transfer in the rat. J Neurochem. 1980;35(6):1382-7.

43. Klepper J, Fischbarg J, Vera JC, Wang D, De Vivo DC. GLUT1deficiency: barbiturates potentiate haploinsufficiency in vitro. Pediatr Res. 1999;46(6):677-83.

44. Hao ZF, Cui YX, Li MH, Du D, Liu MF, Tao HQ, et al. Liposomes modified with P-aminophenyl-alpha-D-mannopyranoside: a carrier for targeting cerebral functional regions in mice. Eur J Pharm Biopharm. 2013;84(3):505-16.

45. Georgieva JV, Hoekstra D, Zuhorn IS. Smuggling drugs into the brain: an overview of ligands targeting transcytosis for drug delivery across the blood-brain barrier. Pharmaceutics. 2014;6(4):557-83.

46. Nagamatsu S, Nakamichi Y, Inoue N, Inoue M, Nishino H, Sawa H. Rat C6 glioma cell growth is related to glucose transport and metabolism. Biochem J. 1996;319(Pt 2):477-82.

47. Sakamoto A, Ido T. Liposome targeting to rat brain: effect of osmotic opening of the blood-brain barrier. Brain Res. 1993;629(1):171-5. 